\title{
Upgrade of Gamma Spectrometry Systems for ORNL TRISO Fuel PIE
}

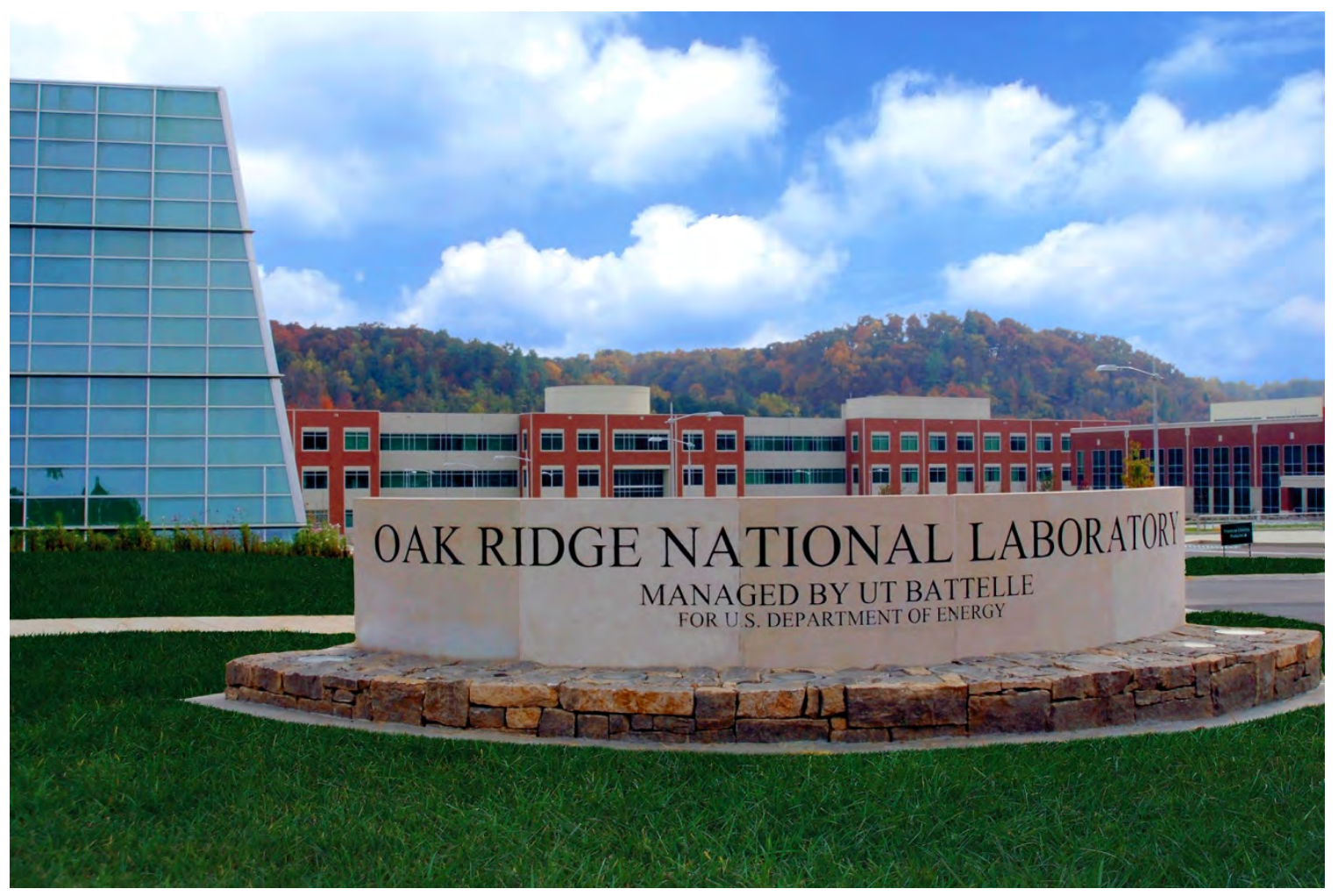

Robert N. Morris

Darren J. Skitt

Charles A. Baldwin

John D. Hunn

Approved for public release.

Distribution is unlimited.

January 2022 


\title{
DOCUMENT AVAILABILITY
}

Reports produced after January 1, 1996, are generally available free via US Department of Energy (DOE) SciTech Connect.

Website www.osti.gov

Reports produced before January 1, 1996, may be purchased by members of the public from the following source:

\author{
National Technical Information Service \\ 5285 Port Royal Road \\ Springfield, VA 22161 \\ Telephone 703-605-6000 (1-800-553-6847) \\ TDD 703-487-4639 \\ Fax 703-605-6900 \\ E-mail info@ntis.gov \\ Website http://classic.ntis.gov/
}

Reports are available to DOE employees, DOE contractors, Energy Technology Data Exchange representatives, and International Nuclear Information System representatives from the following source:

Office of Scientific and Technical Information

PO Box 62

Oak Ridge, TN 37831

Telephone 865-576-8401

Fax 865-576-5728

E-mail reports@osti.gov

Website https://www.osti.gov/

This report was prepared as an account of work sponsored by an agency of the United States Government. Neither the United States Government nor any agency thereof, nor any of their employees, makes any warranty, express or implied, or assumes any legal liability or responsibility for the accuracy, completeness, or usefulness of any information, apparatus, product, or process disclosed, or represents that its use would not infringe privately owned rights. Reference herein to any specific commercial product, process, or service by trade name, trademark, manufacturer, or otherwise, does not necessarily constitute or imply its endorsement, recommendation, or favoring by the United States Government or any agency thereof. The views and opinions of authors expressed herein do not necessarily state or reflect those of the United States Government or any agency thereof. 
Nuclear Energy and Fuel Cycle Division

\title{
UPGRADE OF GAMMA SPECTROMETRY SYSTEMS FOR ORNL TRISO FUEL PIE
}

\author{
Revision 0
}

\author{
Robert N. Morris \\ Darren J. Skitt \\ Charles A. Baldwin \\ John D. Hunn
}

January 2022

\begin{abstract}
Work sponsored by
US DEPARTMENT OF ENERGY

Office of Nuclear Energy-Advanced Reactor Technologies

under the

Advanced Gas Reactor Fuel Development and Qualification Program
\end{abstract}

Prepared by

OAK RIDGE NATIONAL LABORATORY

Oak Ridge, TN 37831-6283

managed by

UT-BATTELLE LLC

for the

US DEPARTMENT OF ENERGY

under contract DE-AC05-00OR22725 



\section{CONTENTS}

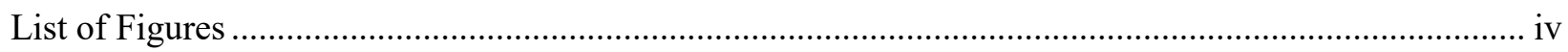

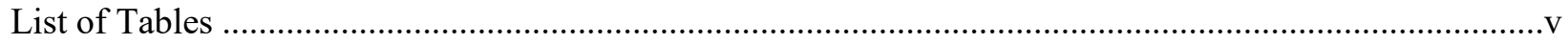

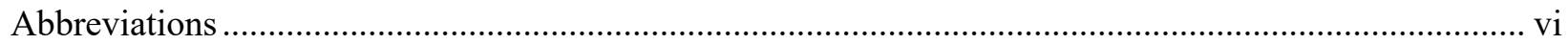

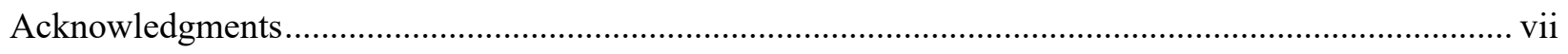

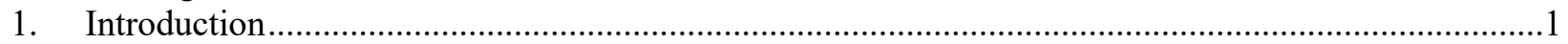

2. Core Conduction Cooldown Test Facility Spectrometer Upgrade ….................................................2

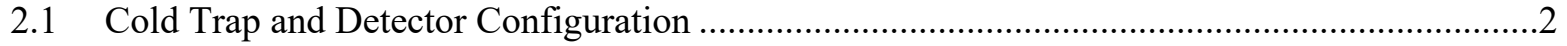

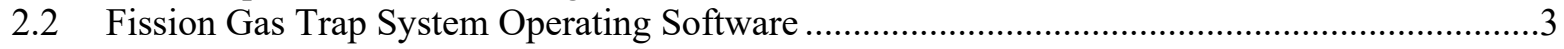

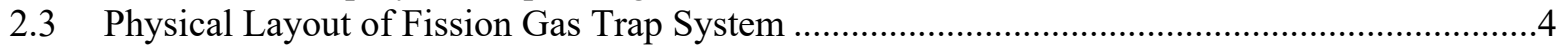

2.4 Krypton-85 Testing and Preliminary Trap Efficiency Determination .....................................

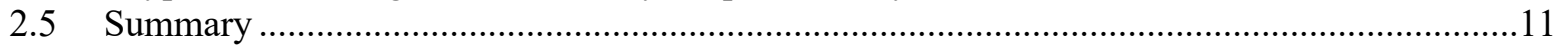

3. Vertical Counting System Spectrometer Upgrade .....................................................................13

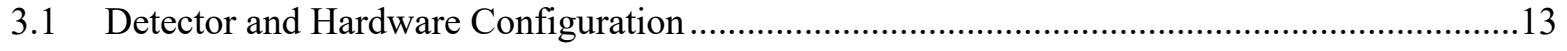

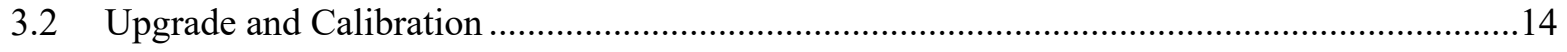

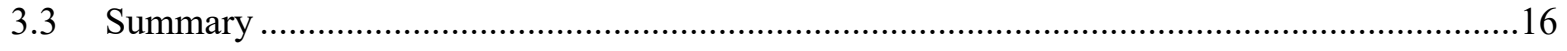

4. Irradiated Microsphere Gamma Analyzer Spectrometer Upgrade .................................................17

4.1 Detector and Hardware Configuration .............................................................................

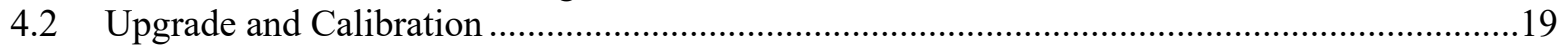

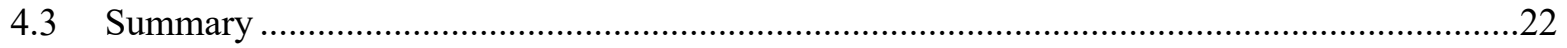

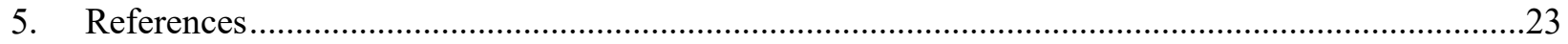

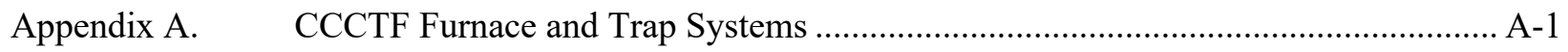

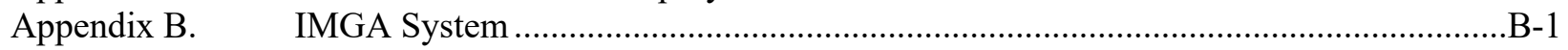




\section{LIST OF FIGURES}

Figure 2-1. CCCTF fission gas trap system and detector configuration................................................

Figure 2-2. Block diagram of the ${ }^{85} \mathrm{Kr}$ gamma counting software interface system..................................

Figure 2-3. CCCTF trap table showing the two fission gas traps, water trap, and valve panel....................5

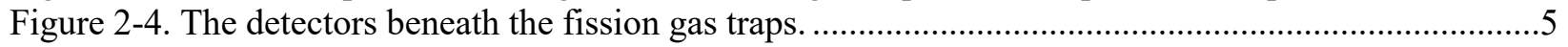

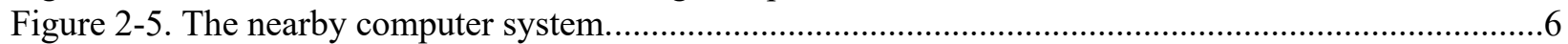

Figure 2-6. Trap with ${ }^{22} \mathrm{Na}$ source placed in the heater port to simulate a ${ }^{85} \mathrm{Kr}$ inventory. ............................6

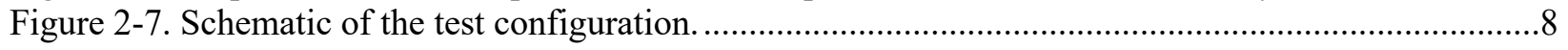

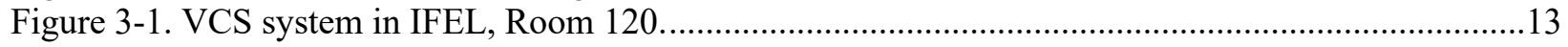

Figure 3-2. Detector and stackable counting stands inside VCS lead-shielded chamber.........................13

Figure 3-3. Examples of VCS counting geometries and calibration standards: (a) point source,

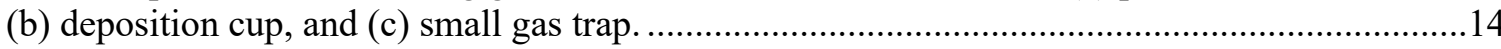

Figure 3-4. Example of data used for calculating efficiencies with deposition cup standard

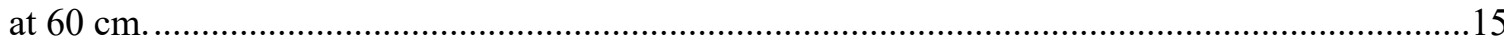

Figure 3-5. Example of calibration curve constructed by ORTEC GammaVision from tabulated

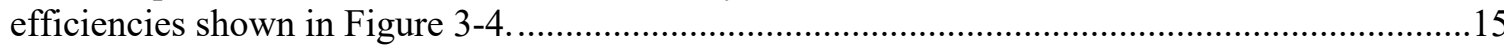

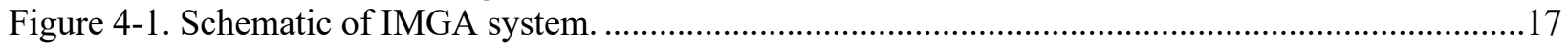

Figure 4-2. View of IMGA particle handling device through the hot cell window showing the

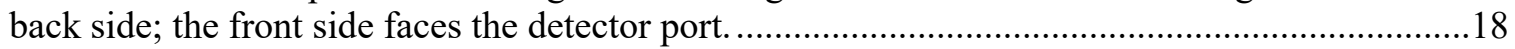

Figure 4-3. Block diagram of IMGA software interface system. .......................................................18 


\section{LIST OF TABLES}

Table 2-1. Results of periodic system checks with a ${ }^{22} \mathrm{Na}$ source ........................................................

Table 2-2. Preliminary efficiency values from ${ }^{85} \mathrm{Kr}$ test .......................................................................

Table 2-3. Trap inventory of ${ }^{85} \mathrm{Kr}$ based on average efficiencies from Table 2-2 .................................10

Table 2-4. Preliminary parameters for the CCCTF trap table detectors ...................................................11

Table 2-5. Two day comparison of old (low activity) and new (high activity) ${ }^{22} \mathrm{Na}$ sources ......................12

Table 4-1. Comparison of measured to fitted energy-dependent efficiencies for particle mode

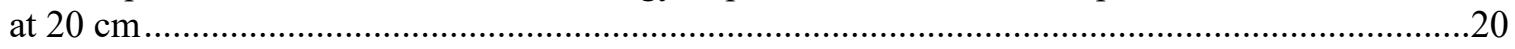

Table 4-2. Comparison of measured to fitted energy-dependent efficiencies for particle mode at $35 \mathrm{~cm}$

Table 4-3. Comparison of measured to fitted energy-dependent efficiencies for particle mode at $50 \mathrm{~cm}$

Table 4-4. Comparison of measured to fitted energy-dependent efficiencies for vial mode at $35 \mathrm{~cm}$

Table 4-5. Comparison of measured to fitted energy-dependent efficiencies for vial mode at $50 \mathrm{~cm}$ 


\section{ABBREVIATIONS}

AGR Advanced Gas Reactor Fuel Qualification and Development (Program)

CCCTF Core Conduction Cooldown Test Facility

DLL dynamic-link library

ENDF/B Evaluated Nuclear Data File

EOI end of irradiation

HPGe high-purity germanium (detector)

HTGR High-Temperature Gas-Cooled Reactor

IMGA Irradiated Microsphere Gamma Analyzer

IFEL Irradiated Fuels Examination Laboratory

MCA multichannel analyzer

NaI sodium iodide (detector)

ORNL Oak Ridge National Laboratory

PIE post-irradiation examination

TRISO tristructural-isotropic (coated particles)

USB Universal Serial Bus

VB.NET Visual Basic .NET (Microsoft programming language)

VCS Vertical Counting System 


\section{ACKNOWLEDGMENTS}

This work was sponsored by the US Department of Energy, Office of Nuclear Energy, Advanced Reactor Technologies as part of the Advanced Gas Reactor Fuel Development and Qualification Program. 



\section{INTRODUCTION}

Gamma spectrometry is a key element in much of the post-irradiation examination (PIE) work performed under the Advanced Gas Reactor Fuel Development and Qualification (AGR) Program (Demkowicz et al. 2015; Stempien et al. 2021). Gamma spectrometers are integrated into three major capabilities used at the Oak Ridge National Laboratory (ORNL) Irradiated Fuels Examination Laboratory (IFEL) for PIE of tristructural-isotropic (TRISO) coated particles and fuel compacts: the Core Conduction Cooldown Test Facility (CCCTF), the Vertical Counting System (VCS), and the Irradiated Microsphere Gamma Analyzer (IMGA). The CCCTF includes liquid-nitrogen-cooled traps to extract ${ }^{85} \mathrm{Kr}$ out of the He sweep gas that passes through the furnace in which the fuel compacts are heated during safety testing. Analysis of the

${ }^{85} \mathrm{Kr}$ activity in the traps is the primary indicator for TRISO failure during safety testing. The VCS is a system used to accurately measure gamma emission from components placed in a lead-shielded chamber. It is used to count the CCCTF deposition cups after removal from furnace. Each cup resides in the CCCTF furnace for typically $12-24 \mathrm{~h}$ and is periodically replaced with a fresh cup throughout the safety test. Metallic fission products collect on the water-cooled cups and several gamma-emitting isotopes $\left({ }^{110 \mathrm{~m}} \mathrm{Ag},{ }^{134} \mathrm{Cs},{ }^{137} \mathrm{Cs},{ }^{154} \mathrm{Eu}\right.$, and $\left.{ }^{155} \mathrm{Eu}\right)$ are often measured and provide indication of the retention performance of the TRISO coatings. The VCS is also used to measure the presence of these isotopes on the CCCTF tantalum liner and sweep gas inlet tube for the determination of cup collection efficiency, as well as support other gamma spectrometry needs related to calibration of the ${ }^{85} \mathrm{Kr}$ fission gas traps and various other special PIE tasks. The IMGA uses gamma spectrometry to measure the inventory of gamma-emitting isotopes in individual TRISO particles. An automated particle handling system within the IMGA hot cell removes each particle from a source vial and positions it in front of a gamma detector, and output from the gamma spectrometer is used by the IMGA software to determine a destination vial such that particles are sorted according to their inventory and retention characteristics.

At the conclusion of the AGR-1 and AGR-2 PIE campaigns, the gamma spectrometer systems used at ORNL to support that PIE had reached the end of its life cycle due to gradual obsolescence of the hardware and software. Upgrade of the Canberra Genie 2000 software used by these systems to a Windows 10 version was not a viable option, because the newest Windows 10 version offered by Mirion (the new owner of the Canberra technology) did not include the dynamic-link libraries (DLLs) needed for integration with the custom PIE software used with the CCCTF and IMGA, and Mirion had no current plans for development and release of Windows 10 versions of these DLLs with the Model S560 Genie 2000 Programming Library. Ultimately a switch was made to ORTEC gamma spectrometry systems, which appeared to be a more sustainable solution due to more proactive vendor support. The ORTEC conversion involved replacing the aging detector preamplifier and multichannel analyzer (MCA) hardware, upgrading the obsolete Windows 7 computers to Windows 10 compatible models, adopting ORTEC GammaVision software, and extensive modification of the ORNL-developed Visual Basic .NET (VB.NET) programs that provide the CCCTF and IMGA user interfaces. 


\section{CORE CONDUCTION COOLDOWN TEST FACILITY SPECTROMETER UPGRADE}

\subsection{COLD TRAP AND DETECTOR CONFIGURATION}

The fuel under test is contained in a high temperature graphite element furnace which is purged by a helium stream. This helium sweep gas is routed into a liquid-nitrogen-cooled charcoal trap system to capture any ${ }^{85} \mathrm{Kr}$ released from the fuel. The details of this system are described in Appendix A and elsewhere (Morris and Baldwin 2010a; Baldwin et al. 2014). A diagram of the fission gas trap system components of interest is shown in Figure 2-1, and additional images and descriptions of the trap system and the CCCTF furnace are provided in Appendix A. Moisture in the gas stream is first removed by a water trap to minimize plugging of the two downstream fission gas traps. The gas stream is routed from the water trap to Trap 1, where the ${ }^{85} \mathrm{Kr}$ is captured. Trap 2 functions as a backup should any ${ }^{85} \mathrm{Kr}$ break through Trap 1. If Trap 1 becomes plugged or malfunctions in some way, the gas stream can be rerouted to Trap 2 while the problems with Trap 1 are resolved. The detectors beneath the traps measure the ${ }^{85} \mathrm{Kr}$ inventory in discrete time intervals. The ${ }^{85} \mathrm{Kr}$ is allowed to accumulate during the entire test period, typically several hundred hours. The trap counting intervals are usually $2-4$ hours, so a safety test results in roughly 50-100 counting intervals, with each interval having a trap inventory equal to or greater than the preceding interval.

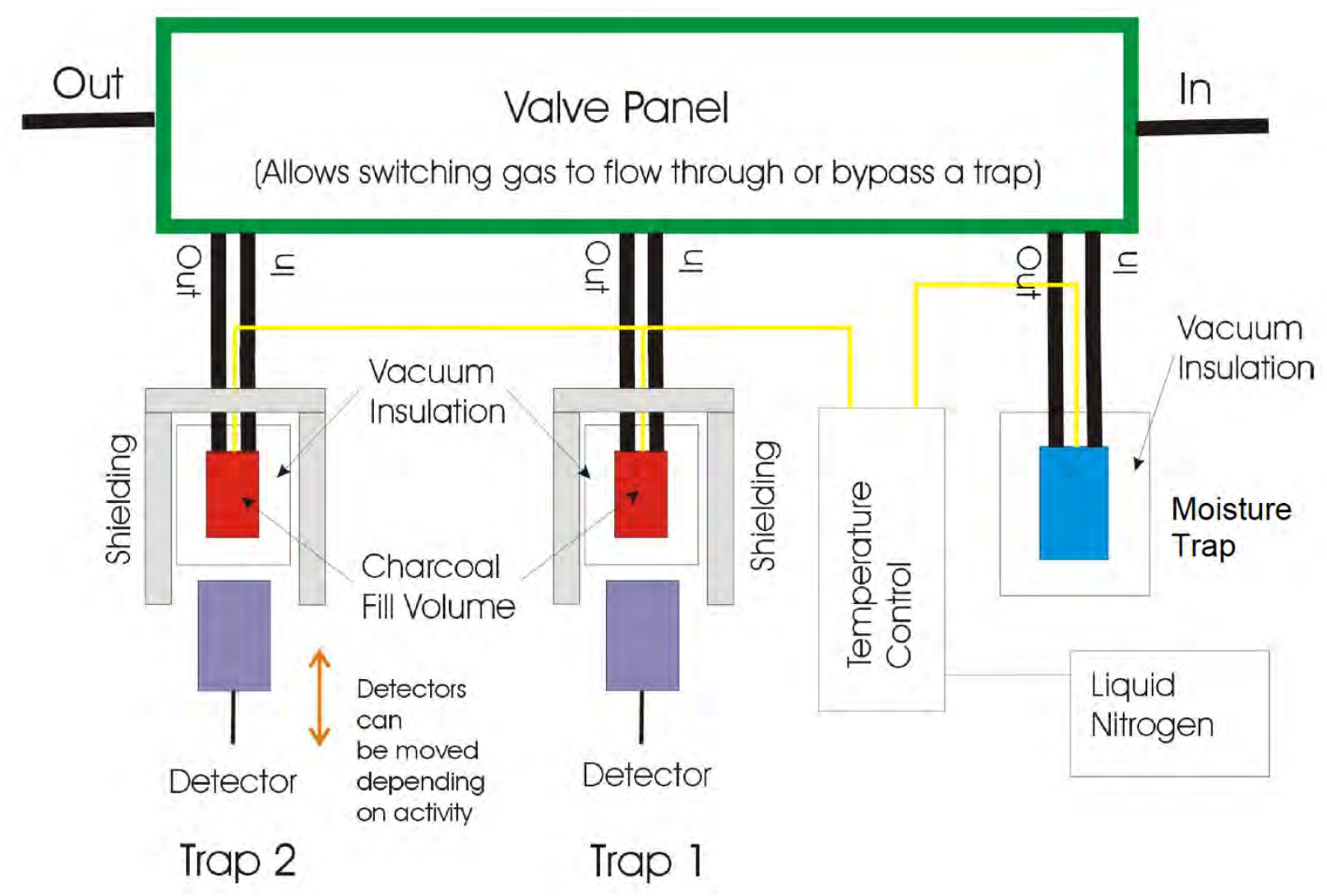

Figure 2-1. CCCTF fission gas trap system and detector configuration (Morris and Baldwin $2010 a$ ). 


\subsection{FISSION GAS TRAP SYSTEM OPERATING SOFTWARE}

The operating software is designed so that the user needs only a minimum of knowledge about the vendor software and detector hardware. The software that controls the detectors performs three main functions:

1. it collects a background prior to the beginning of the test so the ambient gamma background can be subtracted off the measurements,

2. it performs a pretest calibration check using a ${ }^{22} \mathrm{Na}$ source as a proxy for the ${ }^{85} \mathrm{Kr}$ inventory to determine if the system has drifted, and

3. it performs a run, which consists of a repeated sequence of measurements acquired at a user determined interval.

The basic outline of the user interface designed around the ORTEC vendor software is shown in Figure 2-2. As discussed in Section 1, Windows 10 compatibility and vendor support considerations drove a switch from the Genie 2000 software used in the original system to ORTEC GammaVision software. This conversion resulted in both software and hardware changes. An ORTEC system was selected with the DigiBASE integrated MCA and the appropriate software packages: GammaVision for spectrum analysis, GammaVision Report Writer for database management, and the ORTEC CONNECTIONS Programmer's Toolkit for custom software integration with the detector internal hardware.

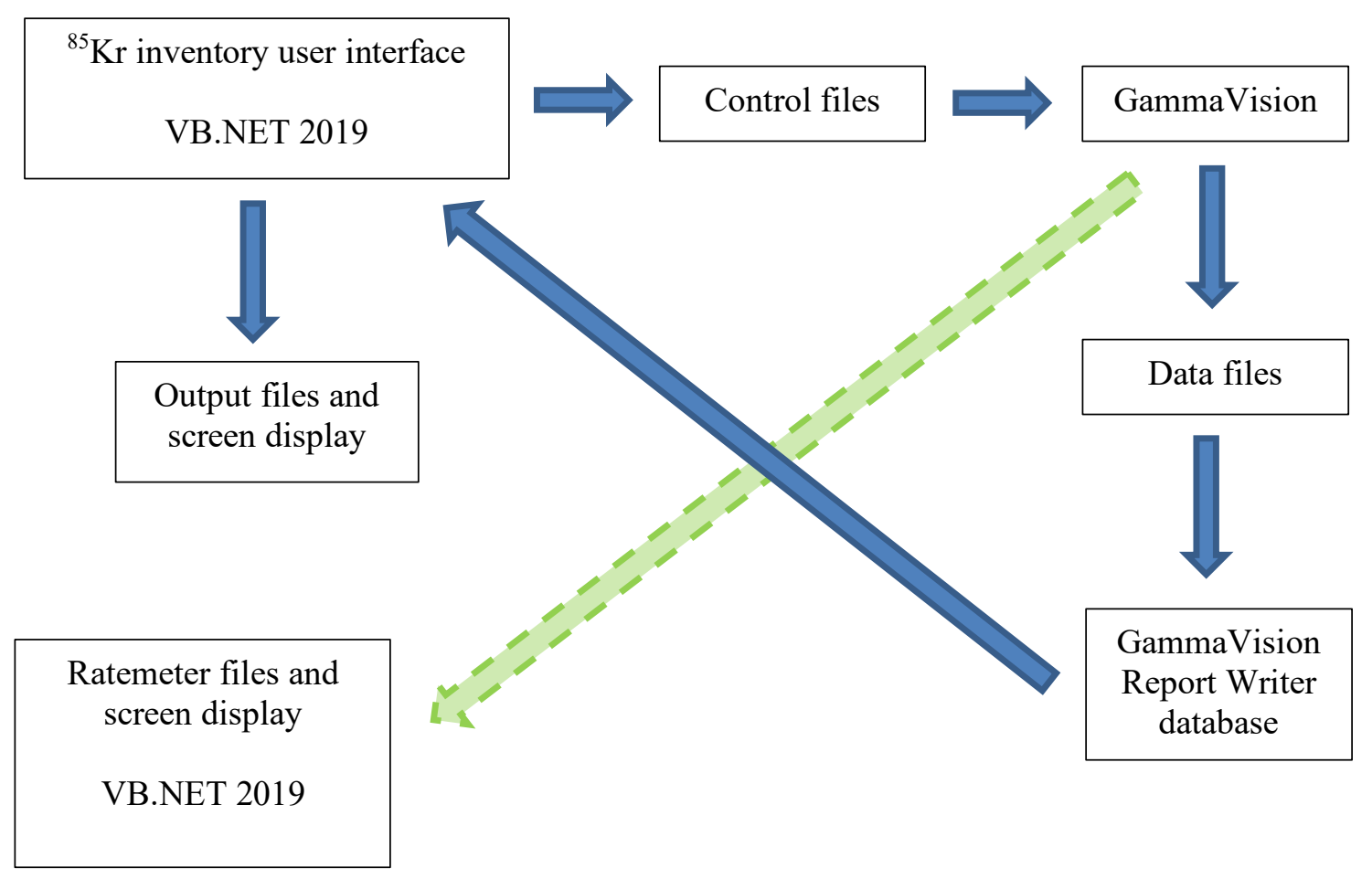

Figure 2-2. Block diagram of the ${ }^{85} \mathrm{Kr}$ gamma counting software interface system.

The system has three modes of operation. The first mode is for background collection. A Windows menu interface allows the user to name the background files, enter description information, and set the counting time. The interface then writes out the appropriate control files and calls the ORTEC software to execute tasks. Once complete, the files are written into the appropriate directory and control returns to the user interface. 
The second mode of operation is for a calibration check. A known ${ }^{22} \mathrm{Na}$ source is inserted into the cold trap heater port and the user interface asks for the half-life and activity level of the source, as well as a description. Once entered, the activity of the source is measured and compared to the known value, which allows a detector efficiency to be computed. This efficiency can then be compared with historical values to determine if the system calibration has drifted. Each detector is checked separately.

The third mode of operation is collecting data during an experiment. In this case, the user enters a run descriptor, a counting time, and the background files. The program then runs indefinitely, collecting trap inventories at the determined interval. The user terminates the run either by allowing it to complete the last count or by stopping it immediately and losing the data from the last counting period.

An auxiliary ratemeter program can be run in the background. This program continuously monitors the output of the detectors in a selected energy interval and displays the results on the screen, in addition to logging them in an output file. The user selects the energy interval of interest, a running average time constant, and an output filename. The program then runs until stopped. While the ratemeter results are only a relative indication of the test behavior, it allows second-by-second monitoring of the ${ }^{85} \mathrm{Kr}$ trap accumulation to pinpoint any sudden change in ${ }^{85} \mathrm{Kr}$ inventory.

\subsection{PHYSICAL LAYOUT OF FISSION GAS TRAP SYSTEM}

The equipment for the detector system and its support is located in Room 128 of IFEL (Building 3525). This system operates independently of the CCCTF furnace control software; thus, in the event of any furnace problems, ${ }^{85} \mathrm{Kr}$ release data can still be collected. The power source is backed up by an uninterruptable power supply. The detectors are located under the trap table and the computer system is located nearby and connected via Universal Serial Bus (USB) cables. The computer is connected to the laboratory network by an Ethernet cable. Figure 2-3 shows the trap table with the gas flow lines and liquid nitrogen supply, Figure 2-4 shows the sodium iodide (NaI) detectors located beneath the cold traps, and Figure 2-5 shows the computer system. For this upgrade, the Trap 1 detector was replaced with a similar on-hand detector that appeared to be slightly better (less drift with count rate), and the original Trap 2 detector was used as none of the others on-hand appeared to be better.

The new detector hardware was installed by removing the old equipment and replacing it with the new equipment. The rest of the system: traps, gas lines, liquid nitrogen supply, and physical supports were not changed or modified. A ${ }^{22} \mathrm{Na}$ source is used as a surrogate gamma source to simulate the presence of ${ }^{85} \mathrm{Kr}$ in each trap via the ${ }^{22} \mathrm{Na} 511 \mathrm{keV}$ gamma ray. While ${ }^{85} \mathrm{Kr}$ freezes out in the traps in a diffuse manner and the ${ }^{22} \mathrm{Na}$ source is effectively a point source at only one representative location, the ${ }^{22} \mathrm{Na}$ source is useful to perform simple periodic checks on the system operation and verify that efficiency calibration has not drifted significantly. Prior to the disassembly of the old detectors, electronics, and software, the ${ }^{22} \mathrm{Na}$ source was inserted into each trap through the heater port (Figure 2-6). The Trap 2 count rate was lower than that for Trap 1, but this was consistent with past records for these two traps as shown in Table 2-1.The difference might be explained by minor differences in the heater well geometry and location that may impact source to detector distance and attenuation (note that this distance is greater than and not related to the $\mathrm{Kr}-85$ collection point in the charcoal trap, so the two efficiencies are not strictly comparable). After the new detector hardware and software was installed, the same ${ }^{22} \mathrm{Na}$ source was remeasured and count rates were consistent with the rate measure before the upgrade. This provided some confidence that the two systems were producing similar results. A new ${ }^{22} \mathrm{Na}$ source was also measured with the new gamma spectrometer system, and the ratio of the Trap 2 to Trap 1 count rates remained the same. 


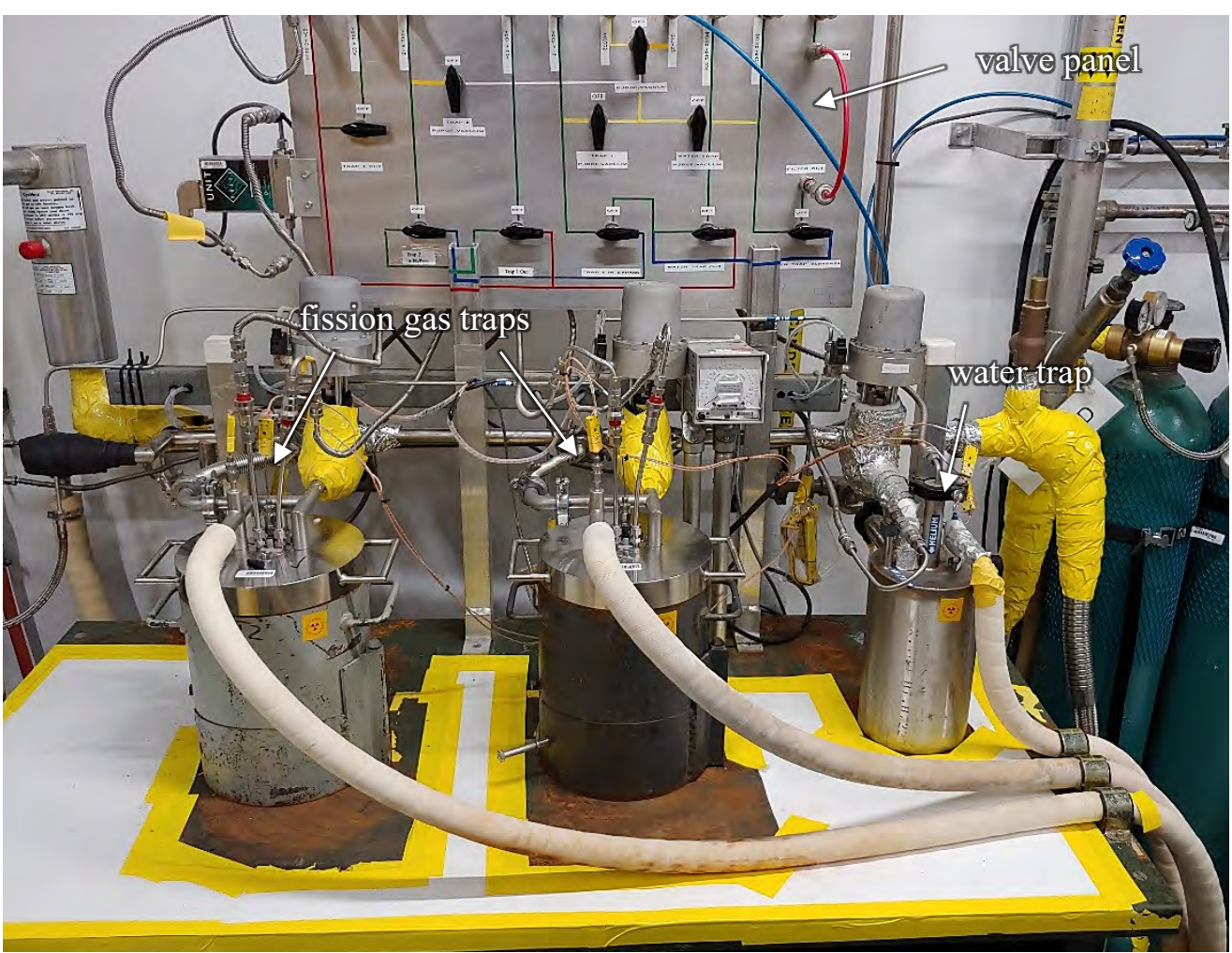

Figure 2-3. CCCTF trap table showing the two fission gas traps, water trap, and valve panel.

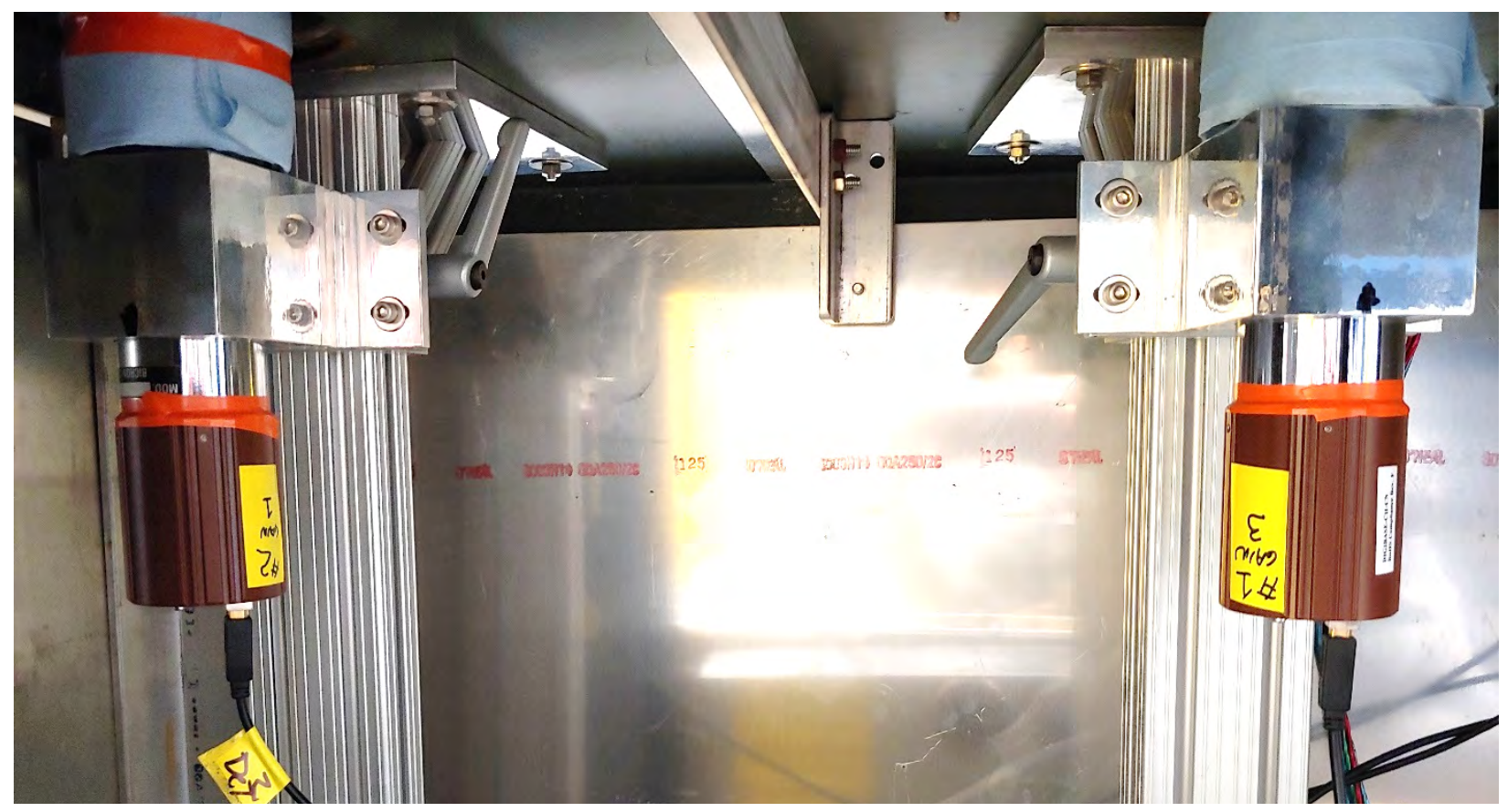

Figure 2-4. The detectors beneath the fission gas traps. 


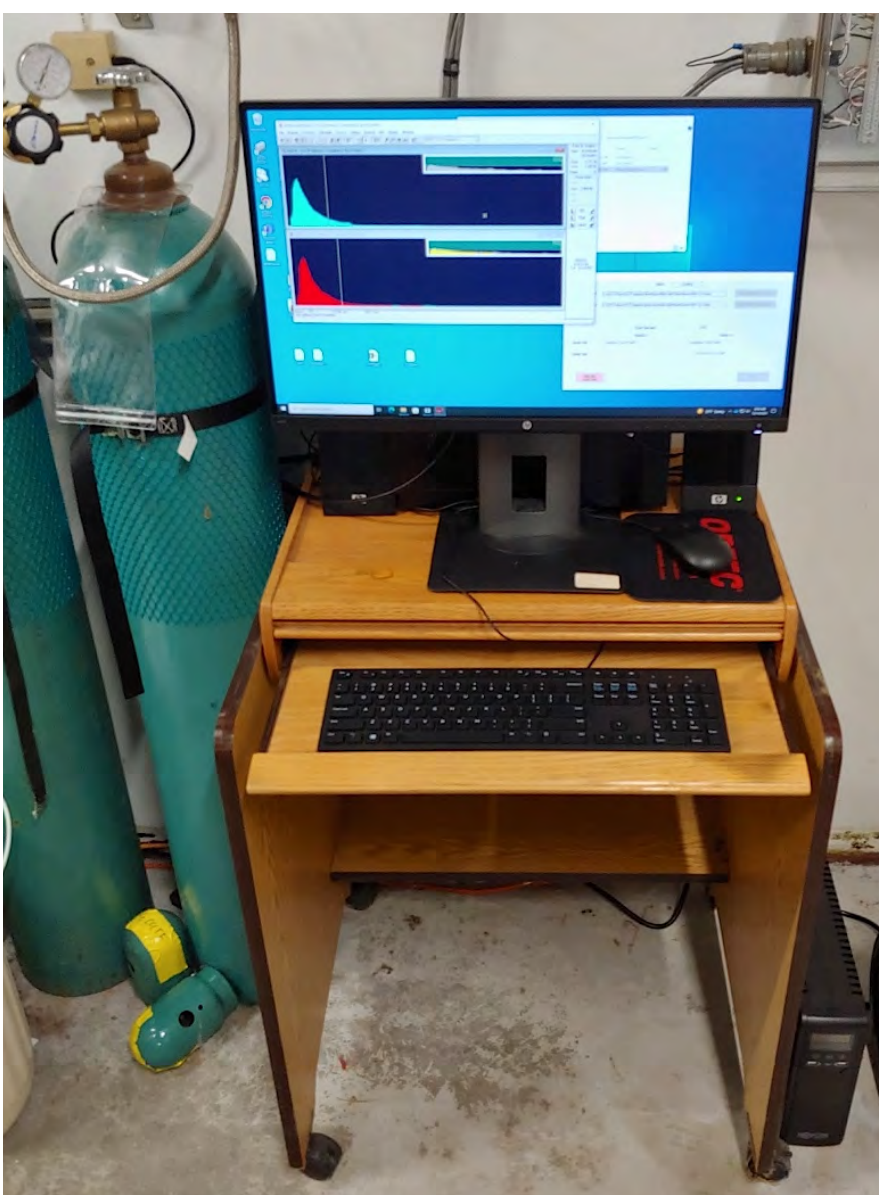

Figure 2-5. The nearby computer system.

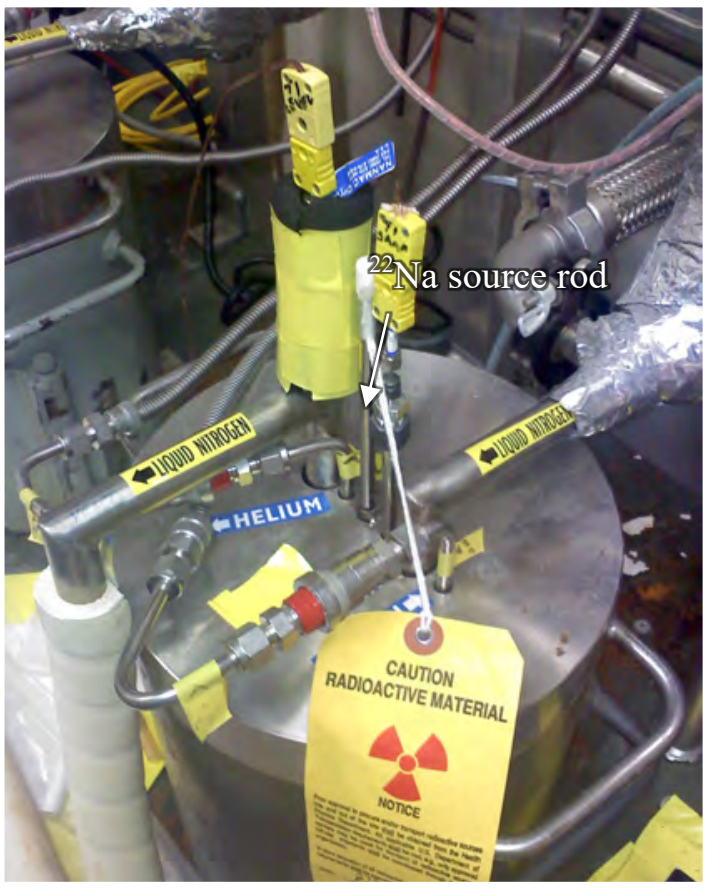

Figure 2-6. Trap with ${ }^{22} \mathrm{Na}$ source placed in the heater port to simulate a ${ }^{85} \mathrm{Kr}$ inventory. 
Table 2-1. Results of periodic system checks with a ${ }^{22} \mathrm{Na}$ source

\begin{tabular}{|c|c|c|c|c|c|}
\hline System & $\begin{array}{c}\text { Date of } \\
{ }^{22} \mathrm{Na} \text { check }\end{array}$ & $\begin{array}{c}\text { Trap 1 } \\
\text { (counts/s) }\end{array}$ & $\begin{array}{c}\text { Trap 2 } \\
\text { (counts/s) }\end{array}$ & $\begin{array}{c}\text { Ratio } \\
\text { (Trap 2/Trap 1) }\end{array}$ & Comments \\
\hline Old Canberra & $6 / 12 / 2017$ & 157.6 & 154.1 & 0.98 & Count rates decrease \\
\hline Old Canberra & $6 / 28 / 2017$ & 156.5 & 151.2 & 0.97 & as ${ }^{22} \mathrm{Na}$ source ages \\
\hline Old Canberra & $8 / 04 / 2017$ & 147.5 & 142.3 & 0.96 & \\
\hline Old Canberra & $8 / 09 / 2017$ & 148 & 141.7 & 0.96 & \\
\hline Old Canberra & $8 / 25 / 2017$ & 149 & 143.7 & 0.96 & \\
\hline Old Canberra & $9 / 08 / 2017$ & 147.5 & 144.1 & 0.98 & \\
\hline Old Canberra & $9 / 18 / 2017$ & 148.7 & 143.4 & 0.96 & \\
\hline Old Canberra & $10 / 10 / 2017$ & 144.6 & 141.1 & 0.98 & \\
\hline Old Canberra & $10 / 16 / 2017$ & 145.1 & 140.2 & 0.97 & \\
\hline Old Canberra & $10 / 31 / 2017$ & 141 & 137.2 & 0.97 & \\
\hline Old Canberra & $11 / 13 / 2017$ & 141.2 & 136.7 & 0.97 & \\
\hline Old Canberra & $11 / 28 / 2017$ & 140.1 & 135.1 & 0.96 & \\
\hline Old Canberra & $12 / 05 / 2017$ & 137.1 & 133.7 & 0.98 & \\
\hline Old Canberra & $1 / 09 / 2018$ & 135.3 & 130.8 & 0.97 & \\
\hline Old Canberra & $1 / 30 / 2018$ & 132.5 & 128.5 & 0.97 & \\
\hline Old Canberra & $2 / 28 / 2018$ & 130.8 & 126.6 & 0.97 & \\
\hline Old Canberra & $3 / 21 / 2018$ & 128.5 & 124.4 & 0.97 & \\
\hline Old Canberra & $5 / 14 / 2018$ & 123.4 & 119.8 & 0.97 & \\
\hline Old Canberra & $5 / 30 / 2018$ & 122.1 & 118.1 & 0.97 & \\
\hline Old Canberra & $8 / 15 / 2018$ & 115.6 & 110.3 & 0.95 & \\
\hline Old Canberra & $8 / 20 / 2018$ & 115.2 & 110.7 & 0.96 & \\
\hline Old Canberra & $8 / 31 / 2018$ & 114.4 & 110.6 & 0.97 & \\
\hline Old Canberra & $10 / 24 / 2018$ & 109.9 & 103.1 & 0.94 & \\
\hline Old Canberra & $11 / 19 / 2018$ & 107.4 & 101.5 & 0.95 & \\
\hline Old Canberra & $6 / 12 / 2019$ & 92.2 & 87.7 & 0.95 & \\
\hline Old Canberra & $7 / 02 / 2019$ & 91.1 & 86.5 & 0.95 & \\
\hline Old Canberra & $7 / 24 / 2019$ & 90.2 & 85.9 & 0.95 & \\
\hline Old Canberra & $8 / 05 / 2019$ & 88.8 & 85.1 & 0.96 & \\
\hline Old Canberra & $8 / 21 / 2019$ & 87.4 & 84 & 0.96 & \\
\hline Old Canberra & $12 / 01 / 2021$ & 46.6 & 43.9 & 0.94 & old ${ }^{22} \mathrm{Na}$ source before upgrade \\
\hline New Ortec & $1 / 4 / 2022$ & 47.2 & 44 & 0.93 & old ${ }^{22} \mathrm{Na}$ source after upgrade \\
\hline New Ortec & $1 / 5 / 2022$ & 3050 & 2850 & 0.93 & new ${ }^{22} \mathrm{Na}$ source \\
\hline New Ortec & $1 / 8 / 2022$ & 3050 & 2810 & 0.92 & \\
\hline New Ortec & $1 / 10 / 2022$ & 3040 & 2790 & 0.92 & \\
\hline
\end{tabular}

\subsection{KRYPTON-85 TESTING AND PRELIMINARY TRAP EFFICIENCY DETERMINATION}

A ${ }^{85} \mathrm{Kr}$ test source was prepared by transferring a small amount of commercially procured ${ }^{85} \mathrm{Kr}$ into a 33-mm-diameter spherical glass container with stopcocks on either side. This sphere was then gamma counted with the VCS to verify that the test value was representative of a single TRISO particle's end of irradiation (EOI) inventory, $\sim 10-15 \mu \mathrm{Ci}$. Because the counting geometry for the glass sphere was not ideal, the activity obtained from this measurement had an approximate uncertainty of $10 \%$. For determination of preliminary ${ }^{85} \mathrm{Kr}$ counting efficiencies, a more accurate value for the ${ }^{85} \mathrm{Kr}$ inventory in the glass sphere was obtained at the end of the testing, as discussed below.

Before releasing the ${ }^{85} \mathrm{Kr}$ contained in the glass sphere into the traps for measurement, two small traps were added to the exit of Trap 2, and a flow of helium was established through the trap system that was 
representative of the nominal furnace flow $(850 \mathrm{sccm})$. The purpose of the two small traps was to capture ${ }^{85} \mathrm{Kr}$ after it was measured in each sweep gas trap, and the small traps provided a well characterized and calibrated geometry that could be more accurately measured using the VCS. Once proper flow had been verified through the trap system and the main traps were cooled down with liquid nitrogen, the sphere containing the ${ }^{85} \mathrm{Kr}$ was connected to the helium inlet and the stopcocks opened to allow all the ${ }^{85} \mathrm{Kr}$ to enter the first trap. See Figure 2-7 for a simplified schematic of the configuration.

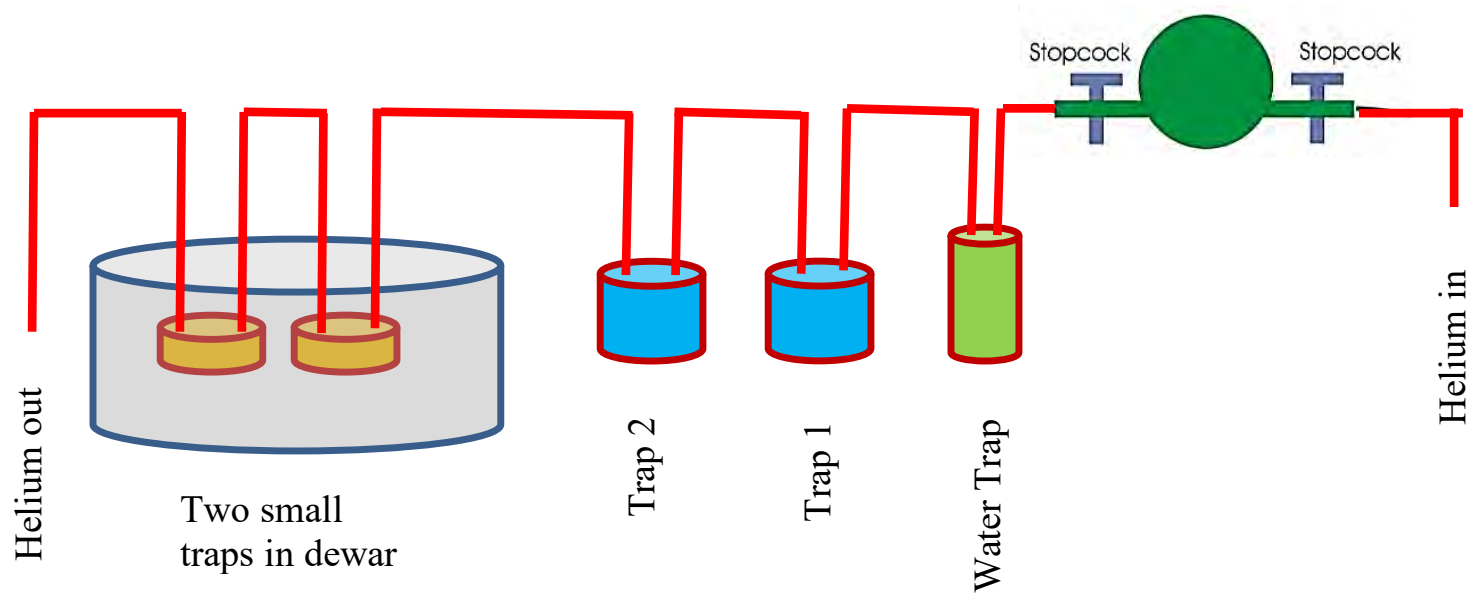

Figure 2-7. Schematic of the test configuration.

The ${ }^{85} \mathrm{Kr}$ froze out in Trap 1 and was allowed to remain there for several counting periods; each counting period had a live time of $3600 \mathrm{~s}$. By measuring the ${ }^{85} \mathrm{Kr}$ activity over several counting periods, a measure of the count-to-count variability was obtained. Trap 1 was then warmed up and the ${ }^{85} \mathrm{Kr}$ was swept into Trap 2, where it again froze out. As with Trap 1, the ${ }^{85} \mathrm{Kr}$ was counted for several cycles. Then, the two small traps at the end of the train were cooled with liquid nitrogen and Trap 2 was warmed up, which transferred the ${ }^{85} \mathrm{Kr}$ to the first of the two small traps. The Water Trap was in continuous operation the entire time. At this point, data had been collected for both Trap 1 and Trap 2; and all that remained was to determine the efficiency ratio of gammas measured to gamma emitted to connect the count rate in each trap with its ${ }^{85} \mathrm{Kr}$ inventory.

Traps 1 and 2 were recounted to verify that all the ${ }^{85} \mathrm{Kr}$ had been moved to the small trap(s). These were then valved off and removed from the trap table. After warming up, the small traps were gamma counted in the VCS, which was calibrated for their specific geometry using a specially designed calibration standard. The ${ }^{85} \mathrm{Kr}$ inventory in the first small trap was determined to be $11.8 \mu \mathrm{Ci}$, with a $4 \%$ estimated uncertainty, while the second small trap held negligible inventory.

Table 2-2 shows the efficiencies determined for each counting period during which the full inventory of ${ }^{58} \mathrm{Kr}$ was present in a trap. The efficiencies measured during each counting period were consistent overall, with all but the ratio for Count 19 falling within two standard deviations of the average efficiency for that trap. The average efficiencies for the two traps were in good agreement as well, which was expected based on the similarity between the physical structure and detector positions for these two nearly identical traps. If Count 19 were not included in the average efficiency for Trap 1, the refined average efficiency value of $0.01717 \pm 0.00015$ would show even closer agreement with the Trap 2 value. 
Table 2-2. Preliminary efficiency values from ${ }^{85} \mathrm{Kr}$ test

\begin{tabular}{|c|c|c|c|c|}
\hline Count & $\begin{array}{l}\text { Date and Time at } \\
\text { Start of } 3600 \text { s Count }\end{array}$ & $\begin{array}{c}\text { Trap } 1 \\
\text { Efficiency }\end{array}$ & $\begin{array}{c}\text { Trap } 2 \\
\text { Efficiency }\end{array}$ & Comments \\
\hline 1 & 12/21/2021 11:12:29 & & & ${ }^{85} \mathrm{Kr}$ transfer to Trap 1 in progress \\
\hline 2 & 12/21/2021 12:12:54 & 0.01748 & & \\
\hline 3 & 12/21/2021 13:13:18 & 0.01739 & & \\
\hline 4 & 12/21/2021 14:13:44 & 0.01719 & & \\
\hline 5 & 12/21/2021 15:14:09 & 0.01705 & & \\
\hline 6 & 12/21/2021 16:14:34 & 0.01725 & & \\
\hline 7 & 12/21/2021 17:14:59 & 0.01713 & & \\
\hline 8 & $12 / 21 / 2021 \quad 18: 15: 24$ & 0.01730 & & \\
\hline 9 & 12/21/2021 19:15:49 & 0.01736 & & \\
\hline 10 & 12/21/2021 20:16:14 & 0.01699 & & \\
\hline 11 & 12/21/2021 21:16:39 & 0.01704 & & \\
\hline 12 & 12/21/2021 22:17:04 & 0.01725 & & \\
\hline 13 & $12 / 21 / 202123: 17: 29$ & 0.01709 & & \\
\hline 14 & $12 / 22 / 20210: 17: 53$ & 0.01699 & & \\
\hline 15 & 12/22/2021 1:18:18 & 0.01704 & & \\
\hline 16 & $12 / 22 / 20212: 18: 43$ & 0.01717 & & \\
\hline 17 & 12/22/2021 3:19:08 & 0.01703 & & \\
\hline 18 & $12 / 22 / 20214: 19: 33$ & 0.01712 & & \\
\hline 19 & $12 / 22 / 20215: 19: 58$ & 0.01643 & & \\
\hline 20 & $12 / 22 / 20216: 20: 23$ & & & ${ }^{85} \mathrm{Kr}$ transfer from Trap 1 to Trap 2 in progress \\
\hline 21 & $12 / 22 / 20217: 20: 51$ & & 0.01714 & liquid nitrogen malfunction, frost near Trap 2 \\
\hline 22 & $12 / 22 / 20218: 21: 19$ & & 0.01739 & \\
\hline 23 & 12/22/2021 9:51:06 & & 0.01707 & minor adjustment to Trap 2 preamp gain \\
\hline 24 & 12/22/2021 10:51:34 & & 0.01737 & \\
\hline 25 & 12/22/2021 11:52:02 & & 0.01729 & \\
\hline 26 & $12 / 22 / 2021 \quad 12: 52: 30$ & & 0.01695 & \\
\hline 27 & $12 / 22 / 202113: 52: 58$ & & 0.01727 & \\
\hline 28 & $12 / 22 / 2021 \quad 14: 53: 26$ & & 0.01748 & \\
\hline 29 & 12/22/2021 15:53:54 & & & ${ }^{85} \mathrm{Kr}$ transfer from Trap 2 to small trap in progress \\
\hline 30 & 12/22/2021 16:54:21 & & & Trap 1 and Trap 2 empty \\
\hline \multicolumn{2}{|c|}{ average efficiency } & 0.01713 & 0.01724 & \\
\hline \multicolumn{2}{|c|}{ standard deviation } & 0.00023 & 0.00018 & \\
\hline \multicolumn{2}{|c|}{$\%$ standard deviation } & $1.3 \%$ & $1.0 \%$ & \\
\hline
\end{tabular}

Note: Efficiency was based on $11.8 \mu \mathrm{Ci}^{85} \mathrm{Kr}$ inventory, as measured in the small trap with VCS.

Note: Gray-shaded cells indicate full ${ }^{85} \mathrm{Kr}$ inventory was not present.

Table 2-3 shows the individual measurements from each counting period determined with the data processing software using the average efficiency ratios from Table 2-2. Counts 1, 20, and 29 show a reduced inventory because ${ }^{85} \mathrm{Kr}$ was being transferred during these counting periods. The few percent variation in the individual values output for ${ }^{85} \mathrm{Kr}$ activity is well within the accuracy needed to monitor for fractional releases of ${ }^{85} \mathrm{Kr}$ and determine the number of particles with failed TRISO over the ranges expected during a typical safety test (Stempien et al. 2021). 
Table 2-3. Trap inventory of ${ }^{85} \mathrm{Kr}$ based on average efficiencies from Table 2-2

\begin{tabular}{|c|c|c|c|c|}
\hline Count & $\begin{array}{l}\text { Date and Time at } \\
\text { Start of } 3600 \text { s Count }\end{array}$ & $\begin{array}{l}\text { Trap } 1 \\
(\mu \mathrm{Ci})\end{array}$ & $\begin{array}{l}\text { Trap } 2 \\
(\mu \mathrm{Ci})\end{array}$ & Comments \\
\hline 1 & 12/21/2021 11:12:29 & 8.21 & 0.00 & ${ }^{85} \mathrm{Kr}$ transfer to Trap 1 in progress \\
\hline 2 & $12 / 21 / 2021 \quad 12: 12: 54$ & 12.05 & 0.00 & \\
\hline 3 & 12/21/2021 13:13:18 & 11.98 & 0.00 & \\
\hline 4 & 12/21/2021 14:13:44 & 11.84 & 0.00 & \\
\hline 5 & 12/21/2021 15:14:09 & 11.75 & 0.00 & \\
\hline 6 & $12 / 21 / 2021 \quad 16: 14: 34$ & 11.88 & 0.00 & \\
\hline 7 & 12/21/2021 17:14:59 & 11.80 & 0.00 & \\
\hline 8 & $12 / 21 / 2021 \quad 18: 15: 24$ & 11.92 & 0.00 & \\
\hline 9 & 12/21/2021 19:15:49 & 11.96 & 0.00 & \\
\hline 10 & 12/21/2021 20:16:14 & 11.71 & 0.00 & \\
\hline 11 & $12 / 21 / 202121: 16: 39$ & 11.74 & 0.00 & \\
\hline 12 & 12/21/2021 22:17:04 & 11.88 & 0.00 & \\
\hline 13 & $12 / 21 / 202123: 17: 29$ & 11.77 & 0.00 & \\
\hline 14 & $12 / 22 / 20210: 17: 53$ & 11.71 & 0.00 & \\
\hline 15 & 12/22/2021 1:18:18 & 11.74 & 0.00 & \\
\hline 16 & $12 / 22 / 20212: 18: 43$ & 11.83 & 0.00 & \\
\hline 17 & 12/22/2021 3:19:08 & 11.73 & 0.00 & \\
\hline 18 & $12 / 22 / 20214: 19: 33$ & 11.80 & 0.00 & \\
\hline 19 & 12/22/2021 5:19:58 & 11.32 & 0.00 & \\
\hline 20 & $12 / 22 / 20216: 20: 23$ & 9.67 & 0.00 & ${ }^{85} \mathrm{Kr}$ transfer from Trap 1 to Trap 2 in progress \\
\hline 21 & $12 / 22 / 20217: 20: 51$ & 0.00 & 11.73 & liquid nitrogen malfunction, frost near Trap 2 \\
\hline 22 & $12 / 22 / 20218: 21: 19$ & 0.00 & 11.90 & \\
\hline 23 & 12/22/2021 9:51:06 & 0.00 & 11.68 & minor adjustment to Trap 2 preamp gain \\
\hline 24 & 12/22/2021 10:51:34 & 0.00 & 11.88 & \\
\hline 25 & 12/22/2021 11:52:02 & 0.00 & 11.83 & \\
\hline 26 & $12 / 22 / 2021 \quad 12: 52: 30$ & 0.00 & 11.60 & \\
\hline 27 & $12 / 22 / 2021 \quad 13: 52: 58$ & 0.00 & 11.82 & \\
\hline 28 & 12/22/2021 14:53:26 & 0.00 & 11.96 & \\
\hline 29 & $12 / 22 / 2021 \quad 15: 53: 54$ & 0.00 & 4.66 & ${ }^{85} \mathrm{Kr}$ transfer from Trap 2 to small trap in progress \\
\hline 30 & $12 / 22 / 2021 \quad 16: 54: 21$ & 0.00 & 0.00 & Trap 1 and Trap 2 empty \\
\hline \multicolumn{2}{|c|}{ average activity } & 11.80 & 11.80 & \\
\hline \multicolumn{2}{|c|}{ standard deviation } & 0.16 & 0.12 & \\
\hline \multicolumn{2}{|c|}{$\%$ standard deviation } & $1.32 \%$ & $1.03 \%$ & \\
\hline
\end{tabular}

Note: System efficiency was based on $11.8 \mu \mathrm{Ci}^{85} \mathrm{Kr}$ inventory, as measured in the small trap with VCS.

Note: Gray-shaded values not used for averages and standard deviations.

As part of the gamma spectrometer system upgrade, a new ${ }^{22} \mathrm{Na}$ source was purchased because the old one had undergone over seven half-lives of decay (see Table 2-1). Comparison of the two sources showed that the efficiencies of the detectors had a modest dependence on the count rate, since the new source was about $84 \times$ more intense than the old one. This count rate dependence is a known effect, but because all the count rates of interest to date have been low enough, the effect was negligible. However, to use this new source and to measure possible very high releases in the CCCTF (in the range of a few hundred $\mu \mathrm{Ci}$ or more) a correction can be applied. A first order correction to the computed ${ }^{85} \mathrm{Kr}$ inventory as a function of count rate $\left(C_{s}\right)$ is:

$$
{ }_{\text {corrected }}^{85} K r={ }_{\text {computed }}^{85} K r\left(1+\beta C_{s}\right) .
$$


The computed ${ }^{85} \mathrm{Kr}$ inventory comes from the ORTEC GammaVision software. The count rate is determined by dividing the counts in the peak by the live time, both of which are output by the software. The correction constant $(\beta)$ can be determined for each detector using the old and new ${ }^{22} \mathrm{Na}$ sources, and this $\beta$ can be used to calculated a corrected ${ }^{85} \mathrm{Kr}$ inventory with the VB.NET program. If applied, this correction will be very small for the normal range of ${ }^{85} \mathrm{Kr}$ release observed during AGR safety testing. The preliminary efficiencies and $\beta$ values determined during the new gamma spectrometer system shakedown testing are shown in Table 2-4.

Table 2-4. Preliminary parameters for the CCCTF trap table detectors

\begin{tabular}{ccc}
\hline & Efficiency & $\boldsymbol{\beta}$ \\
\hline Trap 1 & 0.01713 & $8.688 \mathrm{E}-5$ \\
Trap 2 & 0.01724 & $1.092 \mathrm{E}-4$ \\
\hline
\end{tabular}

As a final system check, an extended test was performed using both the old and new ${ }^{22} \mathrm{Na}$ sources, in which they were swapped back and forth between the two traps to observe longer term operation. The $\mu \mathrm{Ci}$ values in Table 2-5 come from counting the $511 \mathrm{keV}$ gammas emitted from the ${ }^{22} \mathrm{Na}$ sources and using the same processing applied to the $514 \mathrm{keV}$ gammas emitted from ${ }^{85} \mathrm{Kr}$ to calculate a pseudo ${ }^{85} \mathrm{Kr}$ activity using the ${ }^{85} \mathrm{Kr} 514 \mathrm{keV}$ gamma counting efficiency and $\beta$ values in Table 2-4. The calculated pseudo ${ }^{85} \mathrm{Kr}$ activities from the ${ }^{22} \mathrm{Na}$ sources are not important, what is useful to note is how the values change over time. The results in Table 2-5 indicate consistent behavior over a couple of days for each source. The zero entries midway through the test were to verify that the detectors reported zero when there were no sources present. The NaI detectors can be expected to show some energy drift over time. However, the Trap 2 detector showed a notable change in energy with count rate. The average position of the energy peak measured with the Trap 1 detector was about $5 \mathrm{keV}$ higher for the new source than for the old source. However, this appeared to be mostly due to a slow drift over time, as the values when sources were exchanged between Counts 7 and 8 did not change. In contrast, the average position of the energy peak measured with the Trap 2 detector was about $14 \mathrm{keV}$ higher for the new source than for the old source, and the energy changed by $13 \mathrm{keV}$ when sources were exchanged between Counts 7 and 8 . As previously noted in Table 2-1, the ratio of the Trap 2 to Trap 1 count rates has historically been less than unity. This trend is reflected in the pseudo ${ }^{85} \mathrm{Kr}$ activities as expected, and the ratio of the average activities of 0.90 for the old source and 0.92 for the new source were consistent with the ratios reported in Table 2-1.

\subsection{SUMMARY}

The existing CCCTF ${ }^{85} \mathrm{Kr}$ monitoring system was successfully upgraded to one that is Windows 10 compatible. This upgrade involved modifications that added new ORTEC hardware, vendor-supplied GammaVision software, and custom-written VB.NET 2019 user interface software. Testing indicated that the upgraded system performance is similar to the old system, with only a small difference in the user interface. Full calibration of the new system will be performed after new certified calibration sources are received. 
Table 2-5. Two day comparison of old (low activity) and new (high activity) ${ }^{22} \mathrm{Na}$ sources

\begin{tabular}{|c|c|c|c|c|c|}
\hline Count & $\begin{array}{l}\text { Date and Time at } \\
\text { Start of } 3600 \mathrm{~s} \text { Count }\end{array}$ & $\begin{array}{c}\text { Trap 1 } \\
\text { Energy }(\mathrm{keV})\end{array}$ & $\begin{array}{c}\text { Trap 1 } \\
\text { Activity }(\mu \mathrm{Ci})\end{array}$ & $\begin{array}{c}\text { Trap } 2 \\
\text { Energy }(\mathbf{k e V})\end{array}$ & $\begin{array}{c}\text { Trap } 2 \\
\text { Activity }(\mu \mathrm{Ci}) \\
\end{array}$ \\
\hline 1 & $1 / 06 / 20226: 54: 53$ & 514 & 1398 & 509 & 15.70 \\
\hline 2 & $1 / 06 / 2022$ 7:55:19 & 516 & 1400 & 509 & 15.71 \\
\hline 3 & $1 / 06 / 20228: 55: 44$ & 517 & 1398 & 509 & 16.03 \\
\hline 4 & 1/06/2022 9:56:12 & 517 & 1398 & 509 & 15.82 \\
\hline 5 & $1 / 06 / 202210: 56: 36$ & 517 & 1400 & 508 & 15.71 \\
\hline 6 & 1/06/2022 11:57:01 & 517 & 1399 & 508 & 15.66 \\
\hline 7 & $1 / 06 / 202212: 57: 29$ & 518 & 1402 & 508 & 15.40 \\
\hline 8 & 1/06/2022 13:57:54 & 518 & 17.58 & 521 & 1290 \\
\hline 9 & $1 / 06 / 202215: 02: 58$ & 517 & 17.56 & 522 & 1283 \\
\hline 10 & 1/06/2022 16:08:03 & 516 & 17.30 & 523 & 1281 \\
\hline 11 & $1 / 06 / 2022$ 17:13:08 & 515 & 17.23 & 523 & 1282 \\
\hline 12 & 1/06/2022 18:18:12 & 514 & 17.26 & 523 & 1287 \\
\hline 13 & 1/06/2022 19:23:19 & 514 & 17.29 & 524 & 1289 \\
\hline 14 & $1 / 06 / 2022$ 20:28:26 & 513 & 17.00 & 524 & 1288 \\
\hline 15 & 1/06/2022 21:33:30 & 513 & 17.36 & 523 & 1286 \\
\hline 16 & $1 / 06 / 2022$ 22:38:34 & 512 & 17.54 & 523 & 1286 \\
\hline 17 & 1/06/2022 23:43:41 & 512 & 17.11 & 523 & 1285 \\
\hline 18 & 1/07/2022 0:48:45 & 512 & 17.26 & 523 & 1283 \\
\hline 19 & $1 / 07 / 20221: 53: 53$ & 512 & 17.06 & 523 & 1280 \\
\hline 20 & 1/07/2022 2:58:57 & 511 & 17.06 & 522 & 1286 \\
\hline 21 & 1/07/2022 4:04:02 & 511 & 17.19 & 522 & 1284 \\
\hline 22 & 1/07/2022 5:09:06 & 511 & 17.11 & 521 & 1291 \\
\hline 23 & 1/07/2022 6:14:14 & 511 & 17.58 & 521 & 1287 \\
\hline 24 & $1 / 07 / 20227: 19: 21$ & 514 & 0.00 & 514 & 0.00 \\
\hline 25 & $1 / 07 / 20228: 19: 42$ & 514 & 0.00 & 514 & 0.00 \\
\hline 26 & $1 / 07 / 20229: 20: 05$ & 514 & 0.00 & 514 & 0.00 \\
\hline 27 & $1 / 07 / 2022$ 10:20:26 & 514 & 0.00 & 514 & 0.00 \\
\hline 28 & $1 / 07 / 2022$ 11:20:48 & 514 & 0.00 & 514 & 0.00 \\
\hline 29 & $1 / 07 / 202212: 21: 10$ & 514 & 0.00 & 514 & 0.00 \\
\hline 30 & $1 / 07 / 202213: 21: 32$ & 514 & 0.00 & 514 & 0.00 \\
\hline 31 & $1 / 07 / 2022 \quad 14: 21: 57$ & 514 & 1393 & 511 & 15.16 \\
\hline 32 & $1 / 07 / 2022 \quad 15: 22: 24$ & 517 & 1394 & 511 & 15.56 \\
\hline 33 & 1/07/2022 16:22:49 & 518 & 1390 & 511 & 15.30 \\
\hline 34 & 1/07/2022 17:23:17 & 518 & 1392 & 510 & 15.50 \\
\hline 35 & 1/07/2022 18:23:45 & 519 & 1394 & 511 & 15.39 \\
\hline 36 & 1/07/2022 19:24:12 & 519 & 1396 & 511 & 15.44 \\
\hline 37 & $1 / 07 / 2022$ 20:24:40 & 519 & 1397 & 511 & 15.30 \\
\hline 38 & $1 / 07 / 2022$ 21:25:08 & 519 & 1397 & 509 & 15.37 \\
\hline 39 & 1/07/2022 22:25:35 & 519 & 1397 & 510 & 15.62 \\
\hline 40 & $1 / 07 / 2022$ 23:26:00 & 519 & 1399 & 509 & 15.72 \\
\hline 41 & 1/08/2022 0:26:26 & 519 & 1391 & 510 & 15.80 \\
\hline 42 & 1/08/2022 1:26:51 & 519 & 1391 & 509 & 15.50 \\
\hline 43 & 1/08/2022 2:27:16 & 520 & 1391 & 508 & 15.28 \\
\hline 44 & $1 / 08 / 20223: 27: 44$ & 520 & 1391 & 509 & 15.42 \\
\hline 45 & 1/08/2022 4:28:12 & 520 & 1393 & 509 & 15.94 \\
\hline 46 & $1 / 08 / 20225: 28: 37$ & 520 & 1395 & 508 & 15.62 \\
\hline 47 & $1 / 08 / 2022$ 6:29:02 & 520 & 1394 & 508 & 15.57 \\
\hline \multicolumn{2}{|c|}{ New ${ }^{22} \mathrm{Na}$ source average } & 518 & 1395 & 523 & 1286 \\
\hline \multicolumn{2}{|c|}{$\mathrm{New}^{22} \mathrm{Na}$ source standard deviation } & 2 & 3 & 1 & 3 \\
\hline \multirow{2}{*}{\multicolumn{2}{|c|}{$\begin{array}{l}\text { Old }^{22} \mathrm{Na} \text { source average } \\
\text { Old }{ }^{22} \mathrm{Na} \text { source standard deviation }\end{array}$}} & 513 & 17.28 & 509 & 15.56 \\
\hline & & 2 & 0.20 & 1 & 0.22 \\
\hline
\end{tabular}

Note: The $\mu \mathrm{Ci}$ values in the table come from counting the $511 \mathrm{keV}$ gamma peak from the ${ }^{22} \mathrm{Na}$ sources and calculating a pseudo ${ }^{85} \mathrm{Kr}$ activity using the ${ }^{85} \mathrm{Kr} 514 \mathrm{keV}$ gamma counting efficiency and $\beta$ values in Table 2-4. 


\section{VERTICAL COUNTING SYSTEM SPECTROMETER UPGRADE}

\subsection{DETECTOR AND HARDWARE CONFIGURATION}

The VCS in Room 120 of IFEL consists of a Canberra p-type high-purity germanium (HPGe) detector in a lead-shielded counting chamber, a computer, and an MCA (Figure 3-1). As described in Section 1, this system is intended to measure gamma emission from various CCCTF components as well as support other PIE activities. The detector is oriented vertically in a lead shield and equipped with stackable counting stands to accommodate various source to detector distances (Figure 3-2). The VCS is calibrated with certified standards that have geometries representative of common samples. Figure 3-3 shows examples of a point source, a CCCTF deposition cup, and the small gas trap discussed in Section 2.4.

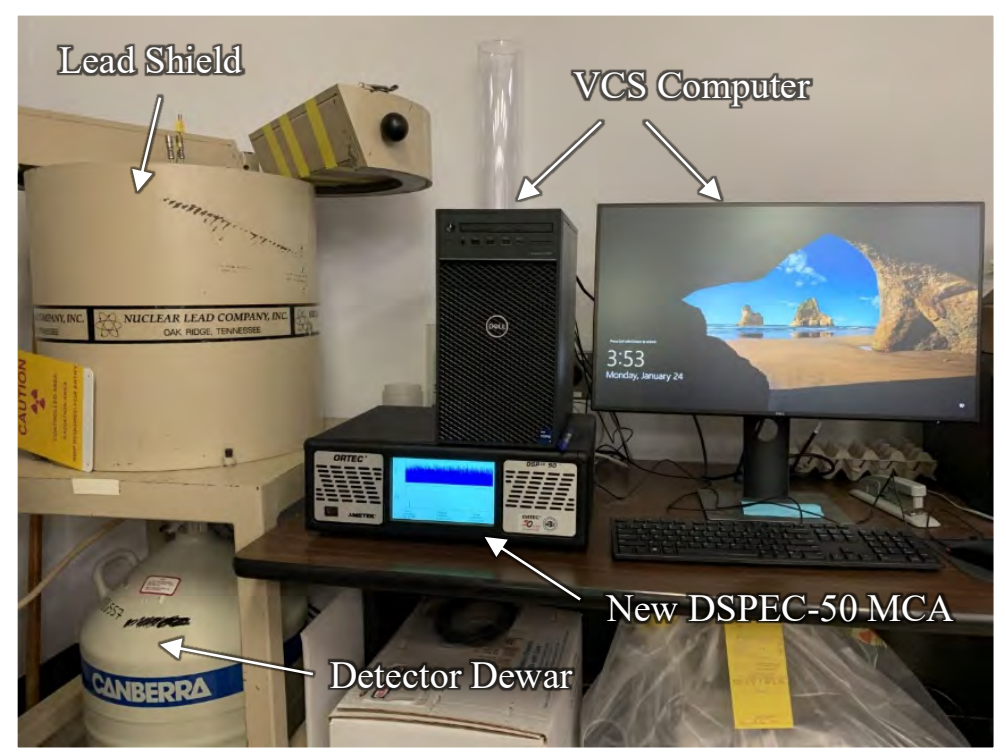

Figure 3-1. VCS system in IFEL, Room 120.

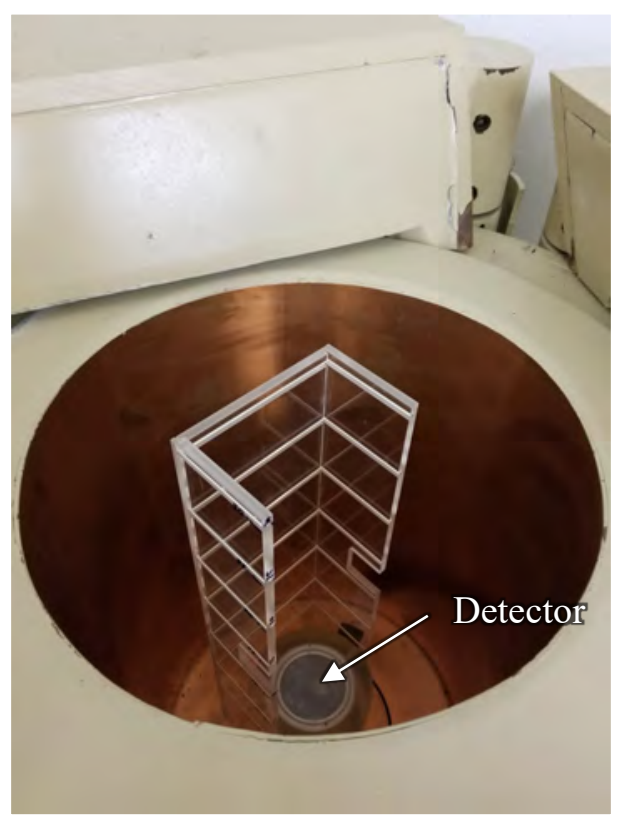

Figure 3-2. Detector and stackable counting stands inside VCS lead-shielded chamber. 


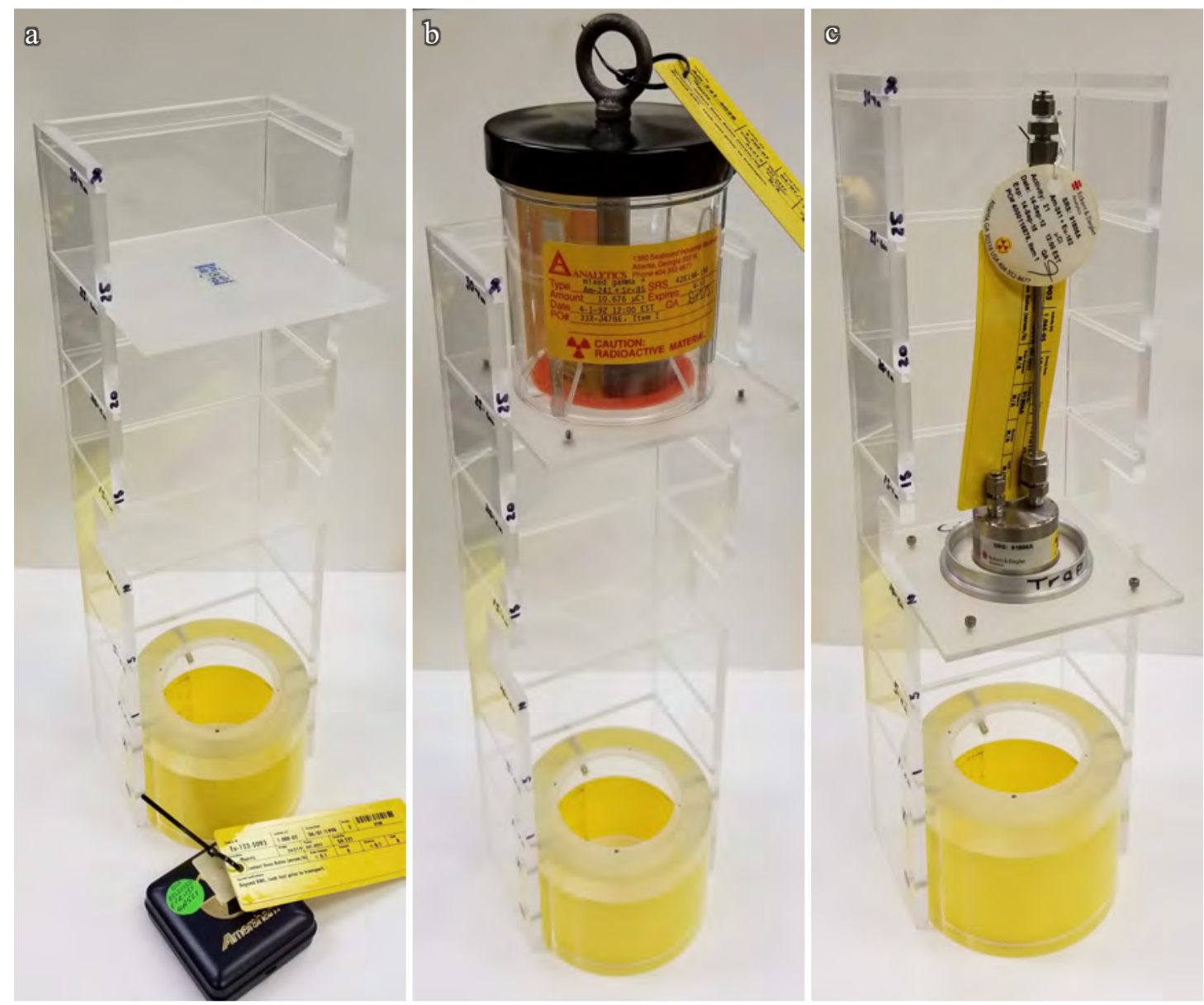

Figure 3-3. Examples of VCS counting geometries and calibration standards: (a) point source, (b) deposition cup, and (c) small gas trap.

\subsection{UPGRADE AND CALIBRATION}

An obsolete computer running Windows XP, a Canberra DSA-1000 MCA, and an old version of the Canberra Genie 2000 software were replaced with a new computer running Windows 10, an ORTEC DSPEC-50 MCA, and the latest ORTEC GammaVision software, respectfully. Previous gamma energy and collection efficiency calibrations associated with the VCS were no longer valid, so the system was recalibrated for the following sample geometries and source-to-detector distances:

1. a point source at $20 \mathrm{~cm}$,

2. a fission gas cold trap at 10 and $20 \mathrm{~cm}$,

3. a deposition cup standard at 15,30 , and $60 \mathrm{~cm}$,

4. a ${ }^{85} \mathrm{Kr}$ glass sphere at $10 \mathrm{~cm}$.

Efficiency curves for each geometry were constructed using measured peaks from certified calibration sources supplied by Eckert and Ziegler Analytics. Half-life and photopeak abundance values were taken from the Evaluated Nuclear Data File (ENDF/B) version VII.1 (Chadwick 2011). Figure 3-4 and Figure 3-5 show an example for the deposition cup calibration source (\#113937) measured at $60 \mathrm{~cm}$, which was a standard deposition cup coated with ${ }^{241} \mathrm{Am},{ }^{137} \mathrm{Cs}$, and ${ }^{152} \mathrm{Eu}$ with a $0.5 \mathrm{mg} / \mathrm{cm}^{2}$ mylar seal coat. Values for photopeaks labeled as not applicable (NA) indicate the number of counts for the radionuclide was too low to accurately resolve. 


\begin{tabular}{|c|c|c|c|c|c|c|c|c|c|c|c|c|c|c|c|c|}
\hline$\Delta$ & A & B & C & D & $\mathrm{E}$ & $\mathrm{F}$ & G & $\mathrm{H}$ & I & J & K & L & M & $\mathrm{N}$ & $\mathrm{O}$ & $P$ \\
\hline 1 & & & & & & & & & & & & & & & & \\
\hline 2 & & & \multicolumn{3}{|c|}{ Reference Date for Activities } & $30-$ Sep-19 & & & & & & & & & & \\
\hline 3 & & & \multicolumn{3}{|c|}{ Counting Date of Source } & 7-Dec-21 & & & & & & & & & & \\
\hline 4 & \multicolumn{5}{|c|}{ /s Between Counting Date and Reference Date } & 799.00 & & & & & & & & & & \\
\hline 5 & & & & & & & & & & Based on & & & \multirow{2}{*}{\multicolumn{4}{|c|}{ VCS Detector 60-cm Bare Geometry }} \\
\hline 6 & & & & & & & & & ENDF7.1 & ENDF7.1 & & Activity on & & & & \\
\hline 7 & Source & & ENDF7.1 & & Decay & Initial & Photopeak & & Photopeak & Initial & & Counting & Counting & Photopeak & Detector & $\begin{array}{l}\text { Detector } \\
\text { Efficiency }\end{array}$ \\
\hline $\begin{array}{l}8 \\
9\end{array}$ & ID & Isotope & Half-Life & Units & $\begin{array}{l}\text { Constant } \\
\text { (sec-1) }\end{array}$ & $\begin{array}{l}\text { Activity } \\
(\mathrm{Bq})\end{array}$ & $\begin{array}{l}\text { Energy } \\
(\mathrm{KeV})\end{array}$ & Type & $\begin{array}{c}\text { Abundance } \\
(\%)\end{array}$ & $\begin{array}{l}\text { Activity } \\
\text { (gps) }\end{array}$ & & $\begin{array}{l}\text { Date } \\
\text { (qps) }\end{array}$ & $\begin{array}{l}\text { Live Time } \\
\text { (sec) }\end{array}$ & $\begin{array}{c}\text { Area } \\
\text { (counts) }\end{array}$ & $\begin{array}{l}\text { Response } \\
\text { (cps) }\end{array}$ & \\
\hline 10 & & & & & & & & & & & & & & & & \\
\hline 11 & 113937 & AM-241 & 432.6 & Y & $5.0773 \mathrm{E}-11$ & $1.872 \mathrm{E}+05$ & 59.54 & q & 35.900 & 67205 & & 66970 & 72000 & $1.70 E+06$ & $2.36 \mathrm{E}+01$ & $3.523 \mathrm{E}-04$ \\
\hline 12 & & & & & & & & & & & & & & & & \\
\hline 13 & 113937 & Cs-137 & 30.08 & Y & $7.3021 \mathrm{E}-10$ & $1.865 \mathrm{E}+05$ & 661.65 & $\mathrm{Ba}-\mathrm{q}$ & 85.100 & 158712 & & 150909 & 72000 & $8.19 E+05$ & $1.14 E+01$ & $7.541 \mathrm{E}-05$ \\
\hline 14 & & & & & & & & & & & & & & & & \\
\hline 15 & 113937 & EU-152 & 13.53 & Y & $1.6234 \mathrm{E}-09$ & $3.755 \mathrm{E}+05$ & 121.78 & $\mathrm{q}$ & 28.670 & 107656 & & 96242 & 72000 & $2.29 \mathrm{E}+06$ & $3.18 \mathrm{E}+01$ & 3.304E-04 \\
\hline 16 & 113937 & EU-152 & 13.53 & Y & $1.6234 \mathrm{E}-09$ & $3.755 \mathrm{E}+05$ & 244.69 & $\mathrm{q}$ & 7.610 & 28576 & & 25546 & 72000 & $3.79 \mathrm{E}+05$ & $5.27 \mathrm{E}+00$ & $63 \mathrm{E}-04$ \\
\hline 17 & 113937 & EU-152 & 13.53 & Y & 1.6234E-09 & $3.755 \mathrm{E}+05$ & 344.27 & q & 26.600 & 99883 & & 89294 & 72000 & $9.62 \mathrm{E}+05$ & $1.34 \mathrm{E}+01$ & $1.496 \mathrm{E}-04$ \\
\hline 18 & 113937 & EU-152 & 13.53 & Y & 1.6234E-09 & $3.755 \mathrm{E}+05$ & 411.11 & $\mathrm{q}$ & 2.237 & 8400 & & 7509 & 72000 & $6.73 \mathrm{E}+04$ & $9.35 \mathrm{E}-01$ & $1.245 \mathrm{E}-04$ \\
\hline 19 & 113937 & EU-152 & 13.53 & Y & $1.6234 \mathrm{E}-09$ & $3.755 \mathrm{E}+05$ & 443.98 & $\mathrm{q}$ & 2.830 & 10627 & & 9500 & 72000 & NA & NA & NA \\
\hline 20 & 113937 & EU-152 & 13.53 & Y & $1.6234 \mathrm{E}-09$ & $3.755 \mathrm{E}+05$ & 488.66 & q & 0.420 & 1577 & & 1410 & 72000 & NA & NA & NA \\
\hline 21 & 113937 & EU-152 & 13.53 & Y & $1.6234 \mathrm{E}-09$ & $3.755 E+05$ & 586.26 & q & 0.472 & 1772 & & 1584 & 72000 & NA & NA & NA \\
\hline 22 & 113937 & EU-152 & 13.53 & $Y$ & $4 \mathrm{E}-09$ & $\mathrm{E}+05$ & 688.63 & $\mathrm{q}$ & 0.859 & 3226 & & 2884 & 72000 & NA & NA & NA \\
\hline 23 & 113937 & EU-152 & 13.53 & Y & 1.6234E-09 & $E+05$ & 778 & q & 12.960 & 48665 & & 43505 & 72000 & $2.09 E+05$ & $2.90 \mathrm{E}+00$ & $6.669 \mathrm{E}-05$ \\
\hline 24 & 113937 & EU-152 & 13.53 & Y & $=-09$ & 3.7 & 867 & $\mathrm{q}$ & 4.260 & 15996 & & 14300 & & +04 & $8.60 \mathrm{E}-01$ & $6.014 \mathrm{E}-05$ \\
\hline 25 & 113937 & EU-152 & 13.53 & Y & $1.6234 \mathrm{E}-09$ & $E+05$ & 964.01 & $\mathrm{q}$ & 14.650 & 55011 & & 49179 & 72000 & $1.95 \mathrm{E}+05$ & $2.71 \mathrm{E}+00$ & $5.501 \mathrm{E}-05$ \\
\hline 26 & 113937 & EU-152 & 13.53 & Y & E-09 & +05 & 1005.06 & $\mathrm{q}$ & 0.648 & 2433 & & 2175 & 72000 & $9.30 \mathrm{E}+03$ & $1.29 \mathrm{E}-01$ & $5.935 \mathrm{E}-05$ \\
\hline 27 & 113937 & EU-152 & 13.53 & Y & $=-09$ & 3.7 & 1085.78 & q & 10.240 & 38451 & & 34375 & 72000 & INA & NA & NA \\
\hline 28 & 113937 & EU-152 & 13.53 & Y & $1.6234 \mathrm{E}-09$ & $E+05$ & 1112.02 & q & 13.690 & 51406 & & 45956 & 72000 & $1.59 \mathrm{E}+05$ & $2.21 \mathrm{E}+00$ & 4.802E-05 \\
\hline 29 & 113937 & EU-152 & 13.53 & Y & 1.62 & 3.7 & & $\mathrm{q}$ & 1.426 & 5355 & & 4787 & & $1.54 \mathrm{E}+04$ & $2.14 \mathrm{E}-01$ & 4.469E-05 \\
\hline 30 & 113937 & EU-152 & 13.53 & Y & E-09 & +05 & & q & 1.652 & 6203 & & 5546 & & $1.65 \mathrm{E}+04$ & $2.29 \mathrm{E}-01$ & 4.134E-05 \\
\hline 31 & 113937 & EU-152 & 13.53 & Y & $E-09$ & +05 & 1407.95 & q & 21.070 & 79118 & & 70730 & 72000 & $1.97 E+05$ & $2.73 \mathrm{E}+00$ & $3.861 \mathrm{E}-05$ \\
\hline 32 & 113937 & EU-152 & 13.53 & Y & 1.62 & 3.7 & & $\mathrm{q}$ & 0.497 & 1866 & & 1668 & & NA & NA & NA \\
\hline 33 & 113937 & EU-152 & 13.53 & Y & 1.6234E-09 & $E+05$ & 1528.65 & $\mathrm{q}$ & 0.279 & 1048 & & 937 & 72000 & NA & NA & NA \\
\hline
\end{tabular}

Figure 3-4. Example of data used for calculating efficiencies with deposition cup standard at $60 \mathrm{~cm}$.

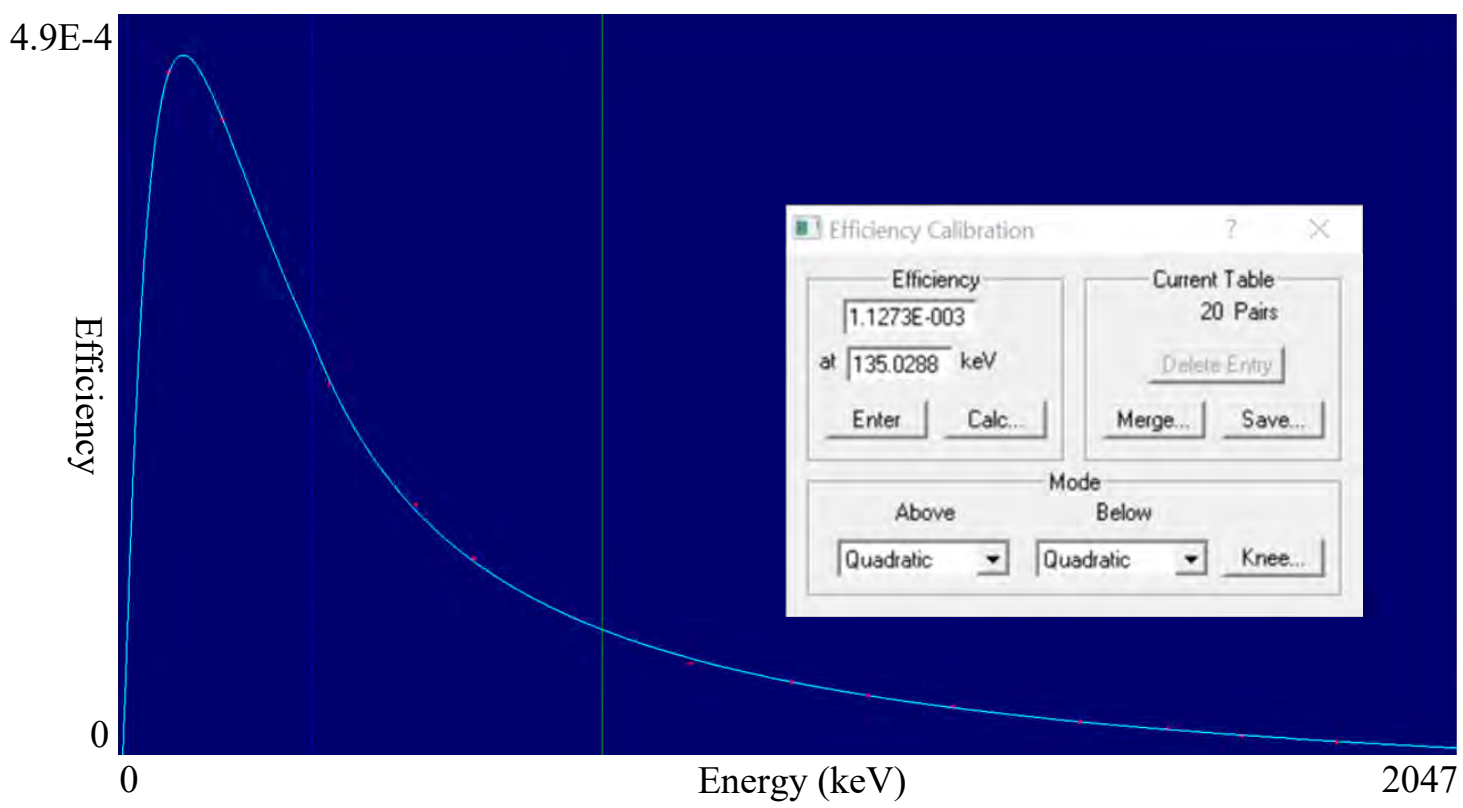

Figure 3-5. Example of calibration curve constructed by ORTEC GammaVision from tabulated efficiencies shown in Figure 3-4.

GammaVision has five different methods for fitting the efficiency as a function of energy: interpolative, linear, quadratic, polynomial, and TCC polynomial. After examining all methods and comparing average delta between measured and fitted efficiencies, the quadratic fitting gave the closest approximation. This method fits a quadratic curve to the natural logarithm of the efficiency versus the natural logarithm of the energy and is described by the equation,

$$
\ln (\varepsilon)=a_{1}+a_{2} \ln (E)+a_{3} \ln (E)^{2},
$$

where $E$ is the energy, $\varepsilon$ is the efficiency at energy $E$, and $a_{i}$ are the fitting coefficients. 


\subsection{SUMMARY}

Conversion has been completed of the VCS Canberra-based gamma spectrometry system to a newer generation ORTEC-based system that is fully supported for Windows 10 operation. Operation of the system was verified and demonstrated using various available sealed sources, and these sources were used to calibrate the system for some of the most often used sample geometries and source-to-detector distances. 


\section{IRRADIATED MICROSPHERE GAMMA ANALYZER SPECTROMETER UPGRADE}

\subsection{DETECTOR AND HARDWARE CONFIGURATION}

The IMGA system currently consists of an ORTEC GMX15P4-70-ST p-type HPGe detector, a three-axis Parker-Daedal motion control apparatus, computer, MCA, and an ORNL-developed VB.NET program designed to automate TRISO particle sorting (Morris and Baldwin 2010b; Hunn et al. 2013). This system is located in the IMGA modular hot cell at IFEL. As depicted in Figure 4-1, the IMGA particle handling device is contained in the modular hot cell while all other IMGA components are located outside of the cell. An in-cell view of the particle handling device is shown in Figure 4-2. Appendix B provides a general description of the IMGA system and includes higher detail views of the device prior to installation into the hot cell. The IMGA particle handling device is used to position individual TRISO particles in front of the beryllium window viewing port, where gammas emitted from the particle can reach the HPGe detector. The IMGA VB.NET software controls the particle handling device's translation stages and uses output from the MCA software to sort particles based on gamma activity criteria entered by the user. As described in Appendix B, the IMGA system can be operated in either particle mode or vial mode. In particle mode, individual particles are removed from a particle hopper and transported to the counting position with a vacuum needle. In vial mode, individual particles are placed in glass vials to retain their identity, and the needle is replaced with a vacuum cup to engage the vial's lid for transport to the gamma counting location.

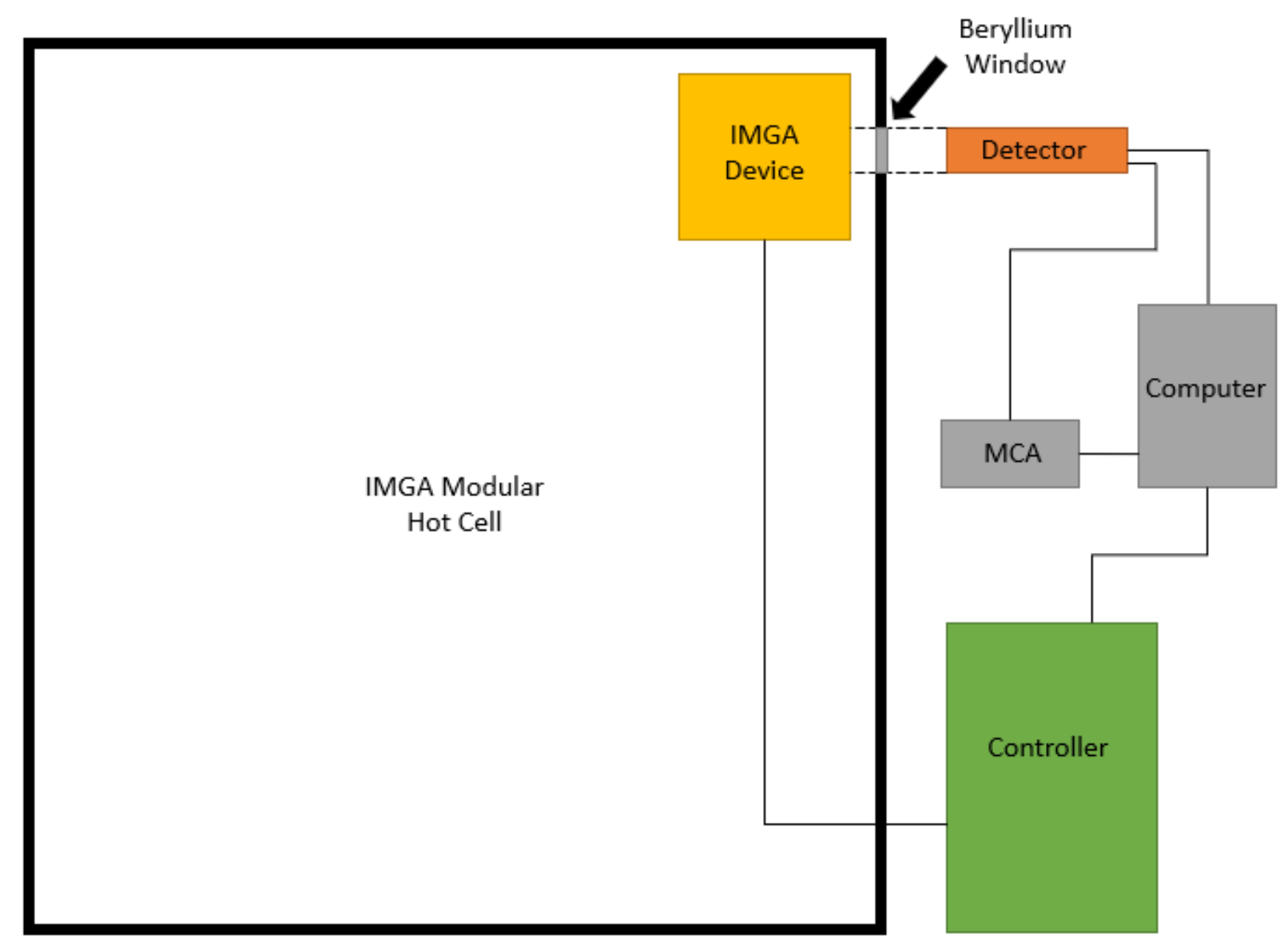

Figure 4-1. Schematic of IMGA system. 


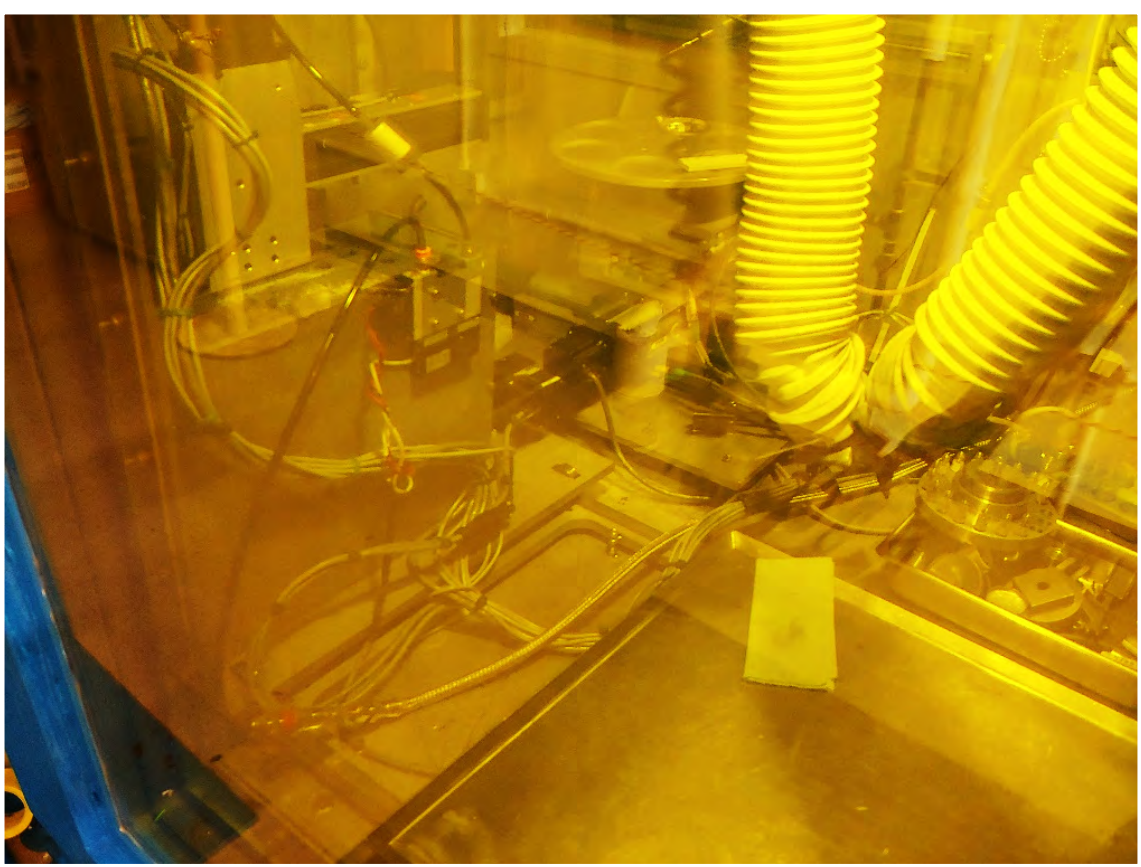

Figure 4-2. View of IMGA particle handling device through the hot cell window showing the back side; the front side faces the detector port.

As discussed in Section 1, Windows 10 compatibility and vendor support considerations drove a switch from the Canberra Genie 2000 software to the ORTEC GammaVision software suite. This change required modification to the IMGA VB.NET user interface and control software to work with the ORTEC software. A basic outline of the VB.NET user interface and motor control system for the IMGA system is shown in Figure 4-3.

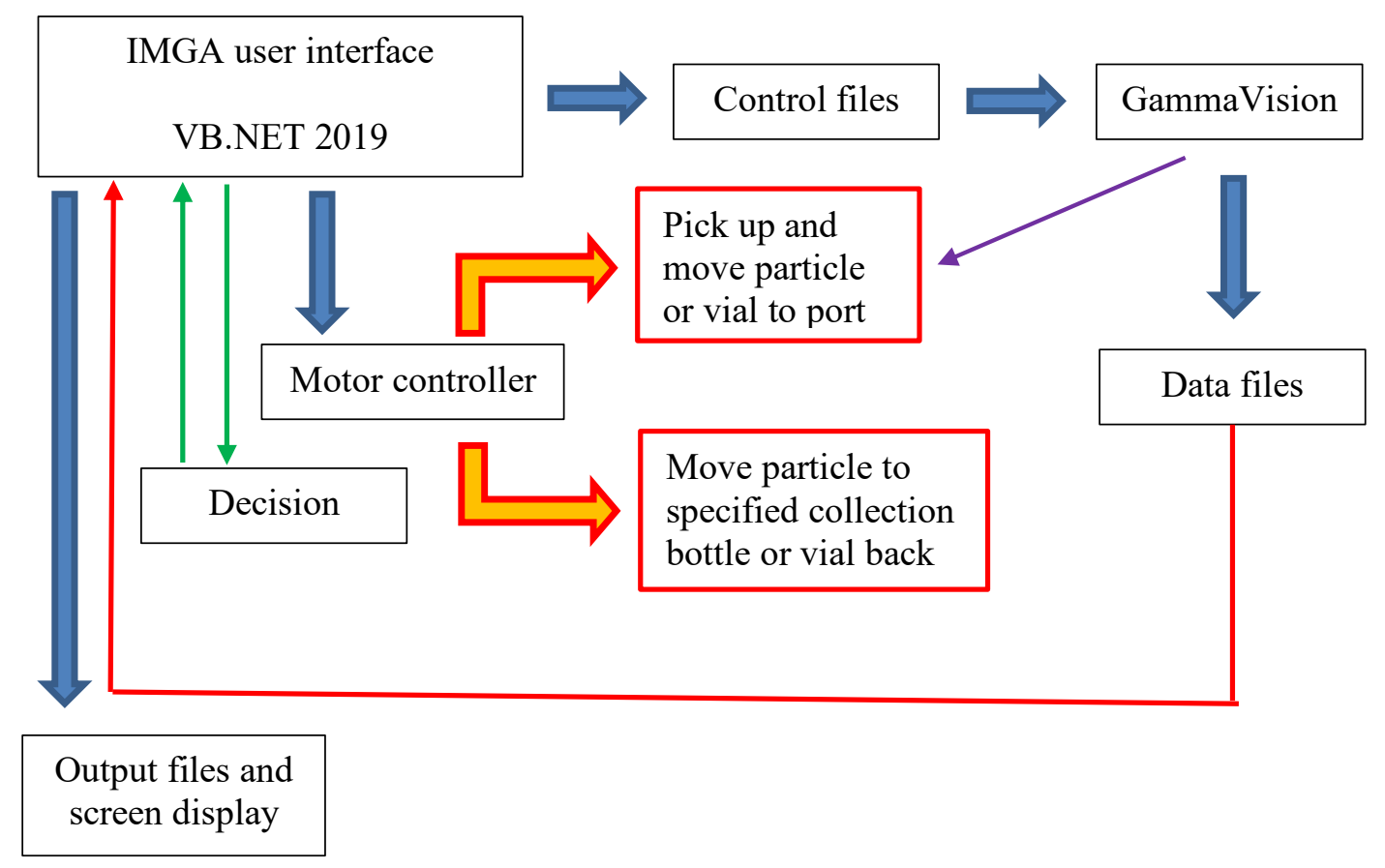

Figure 4-3. Block diagram of IMGA software interface system. 


\subsection{UPGRADE AND CALIBRATION}

Both the IMGA and VCS use an HPGe detector. Upgrade of the IMGA gamma spectrometer system paralleled the reconfiguration of the VCS described in Section 3.2. Obsolete components of the IMGA gamma spectrometer included a Windows XP computer, a Canberra DSA-1000 MCA, and a Windows XP-compatible version of the Canberra Genie 2000 software. These were replaced by a Windows 10 computer, an ORTEC DSPEC-50 MCA, and a Windows 10-compatible version of the ORTEC GammaVision software, respectfully. Some rather extensive modifications to the IMGA VB.NET software were required to accommodate the new hardware and software, but the operation remained the same as that detailed in Section 4.1 and Appendix B.

The IMGA gamma spectrometer system is calibrated with certified point sources to simulate scanning TRISO particles at various source-to-detector distances. Calibrations includes placement of a beryllium disk between the source and detector to account for the attenuation through the hot cell's beryllium window. To achieve calibrations relevant to operation in vial mode, the wall of a glass vial is also placed in line with the detector. The IMGA is used with various source-to-detector distances depending on particle activity. Throughout a PIE campaign, these distances are reduced as the primary gamma-emitting fission products within the TRISO particles decay.

Previous efficiency calibrations were no longer valid after the hardware and software change, so new calibrations were needed. The completed calibrations demonstrate the functionality of the new gamma spectrometer system. Calibrations were obtained for both particle and vial modes with the following source-to-detector distances:

1. operation in particle mode at 20,35 , and $50 \mathrm{~cm}$,

2. operation in vial mode at 35 and $50 \mathrm{~cm}$.

The calibration method was similar to that used for the VCS. As discussed in Section 3.2, the natural logarithm of the measured efficiencies can be fit to a quadratic function of the natural logarithm of the corresponding photopeak energies (see Equation 3.1). Comparisons of the measured efficiencies for the various photopeaks provided by the calibration sources to the efficiencies calculated from the best quadratic fit are presented in Table 4-1 through Table 4-5. The efficiencies determined by the best quadratic fit matched the measured efficiencies to within a few percent in most cases, with only a few efficiencies offset by up to $5.4 \%$. When interpolating efficiencies for a photopeak energy between two calibrated energies, GammaVision automatically calculates the efficiency value for the user using this best fit. This method will be utilized to obtain efficiencies for photopeaks of interest during IMGA data analysis. When compared to the old Canberra system, the ORTEC system's photopeak collection efficiency was lower by an average of $\sim 8 \%$. Besides basic hardware differences, there are a multitude of signal shape/collection parameters that might have contributed to these lower efficiencies. These parameters were chosen by the ORTEC processing software to balance signal resolution versus optimized throughput. 
Table 4-1. Comparison of measured to fitted energy-dependent efficiencies for particle mode at $20 \mathrm{~cm}$

\begin{tabular}{lcccc}
\hline Nuclide & $\begin{array}{c}\text { Peak Energy } \\
\text { (keV) }\end{array}$ & $\begin{array}{c}\text { Measured } \\
\text { Efficiency }\end{array}$ & $\begin{array}{c}\text { Efficiency from } \\
\text { Quadratic Fit }\end{array}$ & $\begin{array}{c}\text { Percent } \\
\text { Difference }\end{array}$ \\
\hline${ }^{133} \mathrm{Ba}$ & 53.16 & $1.448 \mathrm{E}-03$ & $1.445 \mathrm{E}-03$ & $0.22 \%$ \\
${ }^{241} \mathrm{Am}$ & 59.54 & $1.418 \mathrm{E}-03$ & $1.422 \mathrm{E}-03$ & $-0.28 \%$ \\
${ }^{152} \mathrm{Eu}$ & 121.78 & $1.175 \mathrm{E}-03$ & $1.174 \mathrm{E}-03$ & $0.08 \%$ \\
${ }^{152} \mathrm{Eu}$ & 244.69 & $7.707 \mathrm{E}-04$ & $8.035 \mathrm{E}-04$ & $-4.26 \%$ \\
${ }^{133} \mathrm{Ba}$ & 276.40 & $7.025 \mathrm{E}-04$ & $7.069 \mathrm{E}-04$ & $-0.62 \%$ \\
${ }^{133} \mathrm{Ba}$ & 302.84 & $6.599 \mathrm{E}-04$ & $6.429 \mathrm{E}-04$ & $2.58 \%$ \\
${ }^{152} \mathrm{Eu}$ & 344.27 & $5.594 \mathrm{E}-04$ & $5.638 \mathrm{E}-04$ & $-0.78 \%$ \\
${ }^{133} \mathrm{Ba}$ & 356.01 & $5.685 \mathrm{E}-04$ & $5.450 \mathrm{E}-04$ & $4.14 \%$ \\
${ }^{133} \mathrm{Ba}$ & 383.85 & $5.167 \mathrm{E}-04$ & $5.052 \mathrm{E}-04$ & $2.23 \%$ \\
${ }^{152} \mathrm{Eu}$ & 411.11 & $4.719 \mathrm{E}-04$ & $4.718 \mathrm{E}-04$ & $0.03 \%$ \\
${ }^{137} \mathrm{Cs}$ & 661.65 & $2.964 \mathrm{E}-04$ & $2.984 \mathrm{E}-04$ & $-0.69 \%$ \\
${ }^{152} \mathrm{Eu}$ & 778.89 & $2.484 \mathrm{E}-04$ & $2.568 \mathrm{E}-04$ & $-3.38 \%$ \\
${ }^{152} \mathrm{Eu}$ & 867.32 & $2.290 \mathrm{E}-04$ & $2.330 \mathrm{E}-04$ & $-1.76 \%$ \\
${ }^{152} \mathrm{Eu}$ & 964.01 & $2.115 \mathrm{E}-04$ & $2.121 \mathrm{E}-04$ & $-0.29 \%$ \\
${ }^{152} \mathrm{Eu}$ & 1112.02 & $1.848 \mathrm{E}-04$ & $1.872 \mathrm{E}-04$ & $-1.31 \%$ \\
${ }^{152} \mathrm{Eu}$ & 1212.89 & $1.722 \mathrm{E}-04$ & $1.738 \mathrm{E}-04$ & $-0.91 \%$ \\
${ }^{22} \mathrm{Na}$ & 1274.54 & $1.735 \mathrm{E}-04$ & $1.666 \mathrm{E}-04$ & $3.98 \%$ \\
${ }^{152} \mathrm{Eu}$ & 1299.04 & $1.653 \mathrm{E}-04$ & $1.639 \mathrm{E}-04$ & $0.83 \%$ \\
${ }^{60} \mathrm{Co}$ & 1332.49 & $1.611 \mathrm{E}-04$ & $1.605 \mathrm{E}-04$ & $0.40 \%$ \\
${ }^{152} \mathrm{Eu}$ & 1407.95 & $1.523 \mathrm{E}-04$ & $1.532 \mathrm{E}-04$ & $-0.60 \%$ \\
\hline
\end{tabular}

Table 4-2. Comparison of measured to fitted energy-dependent efficiencies for particle mode at $35 \mathrm{~cm}$

\begin{tabular}{lcccc}
\hline Nuclide & $\begin{array}{c}\text { Peak Energy } \\
\text { (keV) }\end{array}$ & $\begin{array}{c}\text { Measured } \\
\text { Efficiency }\end{array}$ & $\begin{array}{c}\text { Efficiency from } \\
\text { Quadratic Fit }\end{array}$ & $\begin{array}{c}\text { Percent } \\
\text { Difference }\end{array}$ \\
\hline${ }^{241} \mathrm{Am}$ & 59.54 & $6.173 \mathrm{E}-04$ & $6.236 \mathrm{E}-04$ & $-1.03 \%$ \\
${ }^{133} \mathrm{Ba}$ & 80.99 & $6.194 \mathrm{E}-04$ & $6.051 \mathrm{E}-04$ & $2.30 \%$ \\
${ }^{152} \mathrm{Eu}$ & 121.78 & $5.341 \mathrm{E}-04$ & $5.431 \mathrm{E}-04$ & $-1.68 \%$ \\
${ }^{152} \mathrm{Eu}$ & 244.69 & $3.502 \mathrm{E}-04$ & $3.650 \mathrm{E}-04$ & $-4.23 \%$ \\
${ }^{133} \mathrm{Ba}$ & 276.40 & $3.226 \mathrm{E}-04$ & $3.203 \mathrm{E}-04$ & $0.70 \%$ \\
${ }^{133} \mathrm{Ba}$ & 302.84 & $2.980 \mathrm{E}-04$ & $2.909 \mathrm{E}-04$ & $2.38 \%$ \\
${ }^{152} \mathrm{Eu}$ & 344.27 & $2.549 \mathrm{E}-04$ & $2.546 \mathrm{E}-04$ & $0.11 \%$ \\
${ }^{133} \mathrm{Ba}$ & 356.01 & $2.544 \mathrm{E}-04$ & $2.460 \mathrm{E}-04$ & $3.30 \%$ \\
${ }^{133} \mathrm{Ba}$ & 383.85 & $2.272 \mathrm{E}-04$ & $2.279 \mathrm{E}-04$ & $-0.29 \%$ \\
${ }^{152} \mathrm{Eu}$ & 411.11 & $2.145 \mathrm{E}-04$ & $2.127 \mathrm{E}-04$ & $0.86 \%$ \\
${ }^{137} \mathrm{Cs}$ & 661.65 & $1.296 \mathrm{E}-04$ & $1.343 \mathrm{E}-04$ & $-3.63 \%$ \\
${ }^{152} \mathrm{Eu}$ & 778.89 & $1.139 \mathrm{E}-04$ & $1.156 \mathrm{E}-04$ & $-1.52 \%$ \\
${ }^{152} \mathrm{Eu}$ & 867.32 & $1.060 \mathrm{E}-04$ & $1.050 \mathrm{E}-04$ & $0.94 \%$ \\
${ }^{152} \mathrm{Eu}$ & 964.01 & $9.729 \mathrm{E}-05$ & $9.568 \mathrm{E}-05$ & $1.66 \%$ \\
${ }^{152} \mathrm{Eu}$ & 1112.02 & $8.314 \mathrm{E}-05$ & $8.460 \mathrm{E}-05$ & $-1.76 \%$ \\
${ }^{152} \mathrm{Eu}$ & 1212.89 & $7.755 \mathrm{E}-05$ & $7.862 \mathrm{E}-05$ & $-1.38 \%$ \\
${ }^{152} \mathrm{Eu}$ & 1299.04 & $7.373 \mathrm{E}-05$ & $7.426 \mathrm{E}-05$ & $-0.72 \%$ \\
${ }^{60} \mathrm{Co}$ & 1332.49 & $7.447 \mathrm{E}-05$ & $7.272 \mathrm{E}-05$ & $2.35 \%$ \\
${ }^{152} \mathrm{Eu}$ & 1407.95 & $7.015 \mathrm{E}-05$ & $6.951 \mathrm{E}-05$ & $0.91 \%$ \\
\hline
\end{tabular}


Table 4-3. Comparison of measured to fitted energy-dependent efficiencies for particle mode at $50 \mathrm{~cm}$

\begin{tabular}{lcccc}
\hline Nuclide & $\begin{array}{c}\text { Peak Energy } \\
\text { (keV) }\end{array}$ & $\begin{array}{c}\text { Measured } \\
\text { Efficiency }\end{array}$ & $\begin{array}{c}\text { Efficiency from } \\
\text { Quadratic Fit }\end{array}$ & $\begin{array}{c}\text { Percent } \\
\text { Difference }\end{array}$ \\
\hline${ }^{241} \mathrm{Am}$ & 59.54 & $3.499 \mathrm{E}-04$ & $3.517 \mathrm{E}-04$ & $-0.53 \%$ \\
${ }^{133} \mathrm{Ba}$ & 80.99 & $3.491 \mathrm{E}-04$ & $3.450 \mathrm{E}-04$ & $1.19 \%$ \\
${ }^{152} \mathrm{Eu}$ & 121.78 & $3.074 \mathrm{E}-04$ & $3.100 \mathrm{E}-04$ & $-0.86 \%$ \\
${ }^{152} \mathrm{Eu}$ & 244.69 & $1.964 \mathrm{E}-04$ & $2.037 \mathrm{E}-04$ & $-3.72 \%$ \\
${ }^{133} \mathrm{Ba}$ & 276.40 & $1.831 \mathrm{E}-04$ & $1.797 \mathrm{E}-04$ & $1.87 \%$ \\
${ }^{133} \mathrm{Ba}$ & 302.84 & $1.647 \mathrm{E}-04$ & $1.637 \mathrm{E}-04$ & $0.60 \%$ \\
${ }^{152} \mathrm{Eu}$ & 344.27 & $1.443 \mathrm{E}-04$ & $1.439 \mathrm{E}-04$ & $0.27 \%$ \\
${ }^{133} \mathrm{Ba}$ & 356.01 & $1.407 \mathrm{E}-04$ & $1.392 \mathrm{E}-04$ & $1.08 \%$ \\
${ }^{133} \mathrm{Ba}$ & 383.85 & $1.301 \mathrm{E}-04$ & $1.292 \mathrm{E}-04$ & $0.70 \%$ \\
${ }^{152} \mathrm{Eu}$ & 411.11 & $1.224 \mathrm{E}-04$ & $1.208 \mathrm{E}-04$ & $1.32 \%$ \\
${ }^{152} \mathrm{Eu}$ & 778.89 & $6.630 \mathrm{E}-05$ & $6.627 \mathrm{E}-05$ & $0.04 \%$ \\
${ }^{152} \mathrm{Eu}$ & 867.32 & $5.750 \mathrm{E}-05$ & $6.019 \mathrm{E}-05$ & $-4.67 \%$ \\
${ }^{152} \mathrm{Eu}$ & 964.01 & $5.508 \mathrm{E}-05$ & $5.482 \mathrm{E}-05$ & $0.47 \%$ \\
${ }^{152} \mathrm{Eu}$ & 1112.02 & $4.819 \mathrm{E}-05$ & $4.843 \mathrm{E}-05$ & $-0.49 \%$ \\
${ }^{60} \mathrm{Co}$ & 1173.21 & $4.656 \mathrm{E}-05$ & $4.626 \mathrm{E}-05$ & $0.66 \%$ \\
${ }^{152} \mathrm{Eu}$ & 1212.89 & $4.448 \mathrm{E}-05$ & $4.496 \mathrm{E}-05$ & $-1.08 \%$ \\
${ }^{152} \mathrm{Eu}$ & 1299.04 & $4.198 \mathrm{E}-05$ & $4.243 \mathrm{E}-05$ & $-1.06 \%$ \\
${ }^{60} \mathrm{Co}$ & 1332.49 & $4.333 \mathrm{E}-05$ & $4.153 \mathrm{E}-05$ & $4.15 \%$ \\
${ }^{152} \mathrm{Eu}$ & 1407.95 & $3.949 \mathrm{E}-05$ & $3.966 \mathrm{E}-05$ & $-0.44 \%$ \\
\hline
\end{tabular}

Table 4-4. Comparison of measured to fitted energy-dependent efficiencies for vial mode at $35 \mathrm{~cm}$

\begin{tabular}{lcccc}
\hline Nuclide & $\begin{array}{c}\text { Peak Energy } \\
\text { (keV) }\end{array}$ & $\begin{array}{c}\text { Measured } \\
\text { Efficiency }\end{array}$ & $\begin{array}{c}\text { Efficiency from } \\
\text { Quadratic Fit }\end{array}$ & $\begin{array}{c}\text { Percent } \\
\text { Difference }\end{array}$ \\
\hline${ }^{241} \mathrm{Am}$ & 59.54 & $5.803 \mathrm{E}-04$ & $5.848 \mathrm{E}-04$ & $-0.78 \%$ \\
${ }^{133} \mathrm{Ba}$ & 80.99 & $5.783 \mathrm{E}-04$ & $5.681 \mathrm{E}-04$ & $1.76 \%$ \\
${ }^{152} \mathrm{Eu}$ & 121.78 & $5.073 \mathrm{E}-04$ & $5.138 \mathrm{E}-04$ & $-1.28 \%$ \\
${ }^{152} \mathrm{Eu}$ & 244.69 & $3.359 \mathrm{E}-04$ & $3.539 \mathrm{E}-04$ & $-5.36 \%$ \\
${ }^{133} \mathrm{Ba}$ & 276.40 & $3.203 \mathrm{E}-04$ & $3.107 \mathrm{E}-04$ & $3.01 \%$ \\
${ }^{133} \mathrm{Ba}$ & 302.84 & $2.853 \mathrm{E}-04$ & $2.822 \mathrm{E}-04$ & $1.10 \%$ \\
${ }^{152} \mathrm{Eu}$ & 344.27 & $2.465 \mathrm{E}-04$ & $2.471 \mathrm{E}-04$ & $-0.24 \%$ \\
${ }^{133} \mathrm{Ba}$ & 356.01 & $2.434 \mathrm{E}-04$ & $2.388 \mathrm{E}-04$ & $1.91 \%$ \\
${ }^{133} \mathrm{Ba}$ & 383.85 & $2.302 \mathrm{E}-04$ & $2.212 \mathrm{E}-04$ & $3.90 \%$ \\
${ }^{152} \mathrm{Eu}$ & 411.11 & $2.037 \mathrm{E}-04$ & $2.065 \mathrm{E}-04$ & $-1.38 \%$ \\
${ }^{137} \mathrm{Cs}$ & 661.65 & $1.271 \mathrm{E}-04$ & $1.309 \mathrm{E}-04$ & $-2.97 \%$ \\
${ }^{152} \mathrm{Eu}$ & 778.89 & $1.106 \mathrm{E}-04$ & $1.129 \mathrm{E}-04$ & $-2.05 \%$ \\
${ }^{152} \mathrm{Eu}$ & 867.32 & $1.007 \mathrm{E}-04$ & $1.026 \mathrm{E}-04$ & $-1.90 \%$ \\
${ }^{152} \mathrm{Eu}$ & 964.01 & $9.495 \mathrm{E}-05$ & $9.361 \mathrm{E}-05$ & $1.41 \%$ \\
${ }^{152} \mathrm{Eu}$ & 1112.02 & $8.309 \mathrm{E}-05$ & $8.293 \mathrm{E}-05$ & $0.20 \%$ \\
${ }^{60} \mathrm{Co}$ & 1173.21 & $8.001 \mathrm{E}-05$ & $7.931 \mathrm{E}-05$ & $0.88 \%$ \\
${ }^{152} \mathrm{Eu}$ & 1212.89 & $7.841 \mathrm{E}-05$ & $7.716 \mathrm{E}-05$ & $1.60 \%$ \\
${ }^{152} \mathrm{Eu}$ & 1299.04 & $7.298 \mathrm{E}-05$ & $7.295 \mathrm{E}-05$ & $0.05 \%$ \\
${ }^{152} \mathrm{Eu}$ & 1407.95 & $6.799 \mathrm{E}-05$ & $6.836 \mathrm{E}-05$ & $-0.55 \%$ \\
\hline
\end{tabular}


Table 4-5. Comparison of measured to fitted energy-dependent efficiencies for vial mode at $50 \mathrm{~cm}$

\begin{tabular}{lcccc}
\hline Nuclide & $\begin{array}{c}\text { Peak Energy } \\
\text { (keV) }\end{array}$ & $\begin{array}{c}\text { Measured } \\
\text { Efficiency }\end{array}$ & $\begin{array}{c}\text { Efficiency from } \\
\text { Quadratic Fit }\end{array}$ & $\begin{array}{c}\text { Percent } \\
\text { Difference }\end{array}$ \\
\hline${ }^{241} \mathrm{Am}$ & 59.54 & $3.212 \mathrm{E}-04$ & $3.234 \mathrm{E}-04$ & $-0.70 \%$ \\
${ }^{133} \mathrm{Ba}$ & 80.99 & $3.287 \mathrm{E}-04$ & $3.235 \mathrm{E}-04$ & $1.57 \%$ \\
${ }^{152} \mathrm{Eu}$ & 121.78 & $2.928 \mathrm{E}-04$ & $2.961 \mathrm{E}-04$ & $-1.14 \%$ \\
${ }^{152} \mathrm{Eu}$ & 244.69 & $1.896 \mathrm{E}-04$ & $1.967 \mathrm{E}-04$ & $-3.76 \%$ \\
${ }^{133} \mathrm{Ba}$ & 276.40 & $1.733 \mathrm{E}-04$ & $1.736 \mathrm{E}-04$ & $-0.18 \%$ \\
${ }^{133} \mathrm{Ba}$ & 302.84 & $1.609 \mathrm{E}-04$ & $1.583 \mathrm{E}-04$ & $1.63 \%$ \\
${ }^{152} \mathrm{Eu}$ & 344.27 & $1.397 \mathrm{E}-04$ & $1.393 \mathrm{E}-04$ & $0.31 \%$ \\
${ }^{133} \mathrm{Ba}$ & 356.01 & $1.377 \mathrm{E}-04$ & $1.347 \mathrm{E}-04$ & $2.15 \%$ \\
${ }^{133} \mathrm{Ba}$ & 383.85 & $1.268 \mathrm{E}-04$ & $1.251 \mathrm{E}-04$ & $1.31 \%$ \\
${ }^{152} \mathrm{Eu}$ & 411.11 & $1.191 \mathrm{E}-04$ & $1.171 \mathrm{E}-04$ & $1.70 \%$ \\
${ }^{152} \mathrm{Eu}$ & 778.89 & $6.317 \mathrm{E}-05$ & $6.479 \mathrm{E}-05$ & $-2.56 \%$ \\
${ }^{152} \mathrm{Eu}$ & 867.32 & $5.678 \mathrm{E}-05$ & $5.895 \mathrm{E}-05$ & $-3.82 \%$ \\
${ }^{152} \mathrm{Eu}$ & 964.01 & $5.453 \mathrm{E}-05$ & $5.381 \mathrm{E}-05$ & $1.33 \%$ \\
${ }^{152} \mathrm{Eu}$ & 1112.02 & $4.730 \mathrm{E}-05$ & $4.766 \mathrm{E}-05$ & $-0.77 \%$ \\
${ }^{60} \mathrm{Co}$ & 1173.21 & $4.493 \mathrm{E}-05$ & $4.558 \mathrm{E}-05$ & $-1.44 \%$ \\
${ }^{152} \mathrm{Eu}$ & 1212.89 & $4.419 \mathrm{E}-05$ & $4.434 \mathrm{E}-05$ & $-0.33 \%$ \\
${ }^{152} \mathrm{Eu}$ & 1299.04 & $4.226 \mathrm{E}-05$ & $4.190 \mathrm{E}-05$ & $0.85 \%$ \\
${ }^{60} \mathrm{Co}$ & 1332.49 & $4.260 \mathrm{E}-05$ & $4.104 \mathrm{E}-05$ & $3.67 \%$ \\
${ }^{152} \mathrm{Eu}$ & 1407.95 & $3.908 \mathrm{E}-05$ & $3.924 \mathrm{E}-05$ & $-0.41 \%$ \\
\hline
\end{tabular}

In addition to the source-to-detector distances that have already been calibrated and discussed above, a source-to-detector distance of $75 \mathrm{~cm}$ was used for AGR-2 $\mathrm{UO}_{2}$ TRISO fuel particles for the first three years after the end of irradiation. The AGR-2 $\mathrm{UO}_{2}$ TRISO particles had a higher overall activity than the AGR-2 UCO TRISO particles due to their larger diameter $\mathrm{UO}_{2}$ kernels ( $500 \mu \mathrm{m}$ for $\mathrm{UO}_{2}$ compared with $425 \mu \mathrm{m}$ for UCO), and this higher overall activity required the longer counting distance. For AGR-2 UCO TRISO particles, a source-to-detector distance of $50 \mathrm{~cm}$ was used for the first three years after EOI, and this distance will likely be sufficient for early IMGA counting of AGR-5/6/7 UCO TRISO fuel particles. A source-to-detector distance of $75 \mathrm{~cm}$ may be calibrated if needed, but only after new calibration sources are procured, because the current set of calibration sources have decayed significantly since they were procured, and stronger sources are needed to promote higher accuracy measurements for the relatively lower efficiencies at this extended distance.

\subsection{SUMMARY}

Procurement and installation of Windows 10-compatible gamma spectrometer hardware and software for the ORNL IMGA are complete. Operation of the upgrade gamma spectrometer system was verified and demonstrated using various available sealed sources, and these sources were used to calibrate the system for the most often used source-to-detector distances for both particle mode and vial mode. As was done for the CCCTF upgrade, the ORNL-developed user interface and control software was also upgraded to VB.NET 2019 for Windows 10 compatibility. To control the IMGA translation stages, the older IMGA VB.NET software used ethernet interface drivers to communicate with the Parker Automation 6K Series four-axis controller, but these drivers are not available for Windows 10. However, the full ethernet capabilities are not needed, and a traditional RS-232 interface option is available. When the ordered parts arrive, the VB.NET control software will be further modified to use the available RS-232 interface to communicate with the $6 \mathrm{~K}$ Series controller. 


\section{REFERENCES}

Baldwin, Charles A., John D. Hunn, Robert N. Morris, Fred C. Montgomery, Chinthaka M. Silva, and Paul A. Demkowicz. 2014. "First Elevated Temperature Performance Testing of Coated Particle Fuel Compacts from the AGR-1 Irradiation Experiment." Nuclear Engineering Design 271: 131-141.

Chadwick, Mark B., et al. 2011. "ENDF/B-VII.1 Nuclear Data for Science and Technology: Cross Sections, Covariances, Fission Product Yields and Decay Data." Nuclear Data Sheets 112, 28872996. Data downloaded from www.nndc.bnl.gov.

Demkowicz, Paul A., John D. Hunn, Robert N. Morris, Isabella J. van Rooyen, Tyler J. Gerczak, Jason M. Harp, and Scott A. Ploger. 2015. AGR-1 Post Irradiation Examination Final Report. INL/EXT15-36407, Revision 0. Idaho Falls: Idaho National Laboratory.

Hunn, John D., Robert N. Morris, Charles A. Baldwin, Fred C. Montgomery, Chinthaka M. Silva, and Tyler J. Gerczak. 2013. AGR-1 Irradiated Compact 4-4-2 PIE Report: Evaluation of As-Irradiated Fuel Performance with Leach Burn Leach, IMGA, Materialography, and X-ray Tomography. ORNL/TM-2013/236, Revision 0. Oak Ridge: Oak Ridge National Laboratory.

Morris, Robert N., and Charles A. Baldwin. 2010a. AGR CCCTF Calibration for Krypton-85 Activity Determination. ORNL/TM-2010/180, Revision 0. Oak Ridge: Oak Ridge National Laboratory.

Morris, Robert N., and Charles A. Baldwin. 2010b. Advanced Irradiated Microsphere Gamma Analyzer Design, Bench Testing, and Installation. ORNL/TM-2010/181, Revision 0. Oak Ridge: Oak Ridge National Laboratory.

Stempien, John D., John D. Hunn, Robert N. Morris, Tyler. J. Gerczak, and Paul A. Demkowicz. 2021. AGR-2 TRISO Fuel Post-Irradiation Examination Final Report. INL/EXT-21-64279, Revision 0. Idaho Falls: Idaho National Laboratory. 



\section{APPENDIX A. CCCTF FURNACE AND TRAP SYSTEMS*}

The Core Conduction Cooldown Test Facility was developed at ORNL in the early 1990s to perform high temperature accident simulation performance tests on coated particle fuels as part of the New Production Modular High Temperature Gas-Cooled Reactor (NP-MHTGR) program in the US. The system has undergone several modifications and now consists of a water-cooled graphite resistance heated tube furnace in a vertical orientation with an internal tantalum container that isolates the test specimens from the furnace heating elements. A helium sweep gas system provides the test atmosphere and transports released fission gases to a cryogenic trap system for collection and gamma counting. Water cooling circuits provide temperature control for sensitive furnace components (including the metal furnace jacket and the cold finger). The furnace system diagram is shown in Appendix Figure A-1, and a photograph of the furnace is shown in Appendix Figure A-2.

A fuel specimen is loaded from the top prior to the start of the run. During operation, a water-cooled cold finger is inserted and removed from the top through an air lock while the fuel is held at temperature. Fuel specimens are housed in a graphite or refractory metal holder that is supported by the tantalum container. This container has a small well for a dual Type $C$ thermocouple, which serves to measure the sample temperature and provide a control input for the furnace control system. The temperature of the tantalum container can also be monitored from the outside through a furnace window using an optical pyrometer. A copper-plated steel deposition cup is attached to the bottom of the cold finger by means of a screw mechanism and acts as the collection surface for condensable metallic fission products. By periodically inserting and removing the cold finger, the deposition cup can be changed, and a time-dependent history of the metallic releases can be obtained. Radiochemical analyses (gamma, beta, and mass spectrometry) provide quantification of the collected elements.

The system is operated in a modular, walk-in hot cell at the IFEL, where the test apparatus can be installed on a campaign basis and removed as needed for maintenance. Fission gases released from the heated fuel are continually swept from the furnace by the helium gas stream and collected in the fission gas trap system, which includes two liquid nitrogen cooled charcoal traps monitored with NaI detectors. The fission gas traps and detectors are located outside of the hot cell in a low background area to facilitate detection of very small quantities of ${ }^{85} \mathrm{Kr}$. A photograph of the fission gas trap assembly is shown in Appendix Figure A-3. A diagram of one of the traps used prior to a redesign in 2017 is shown in Appendix Figure A-4, and Appendix Figure A-5 shows the redesigned trap. The redesigned traps have a charcoal collector module that can be removed from the vacuum insulated dewar and gamma detector shield assembly. This removable module allows for easy replacement of the charcoal should a high releasing experiment contaminate the trap with traces of nongaseous, volatile fission products, such as ${ }^{134} \mathrm{Cs}$ and ${ }^{137} \mathrm{Cs}$.

\footnotetext{
${ }^{*}$ Text and figures in this appendix were extracted, with minor editing, from a previous milestone letter report [Morris and Baldwin 2010a].
} 


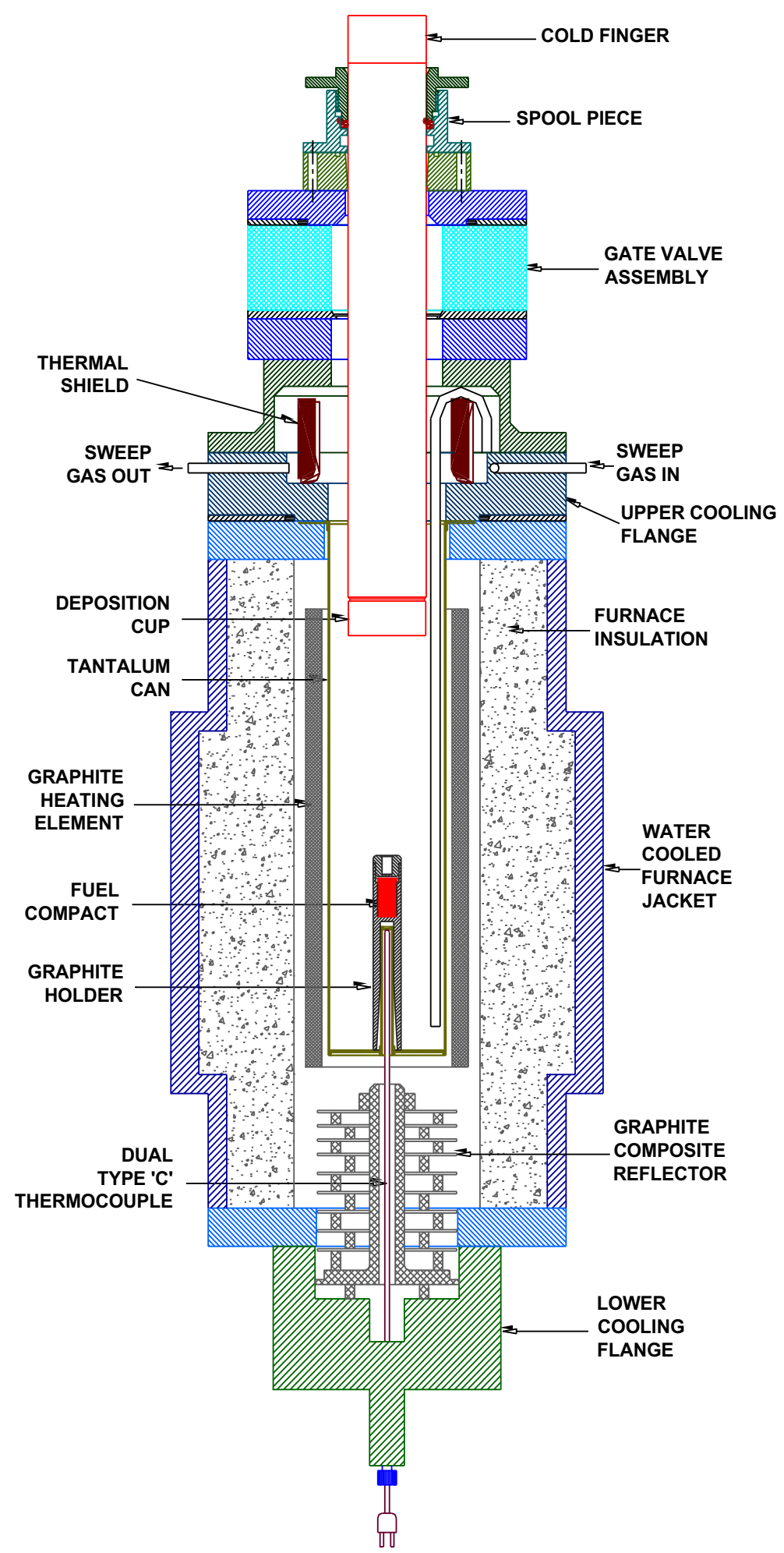

Appendix Figure A-1. Cross section of the CCCTF furnace. 


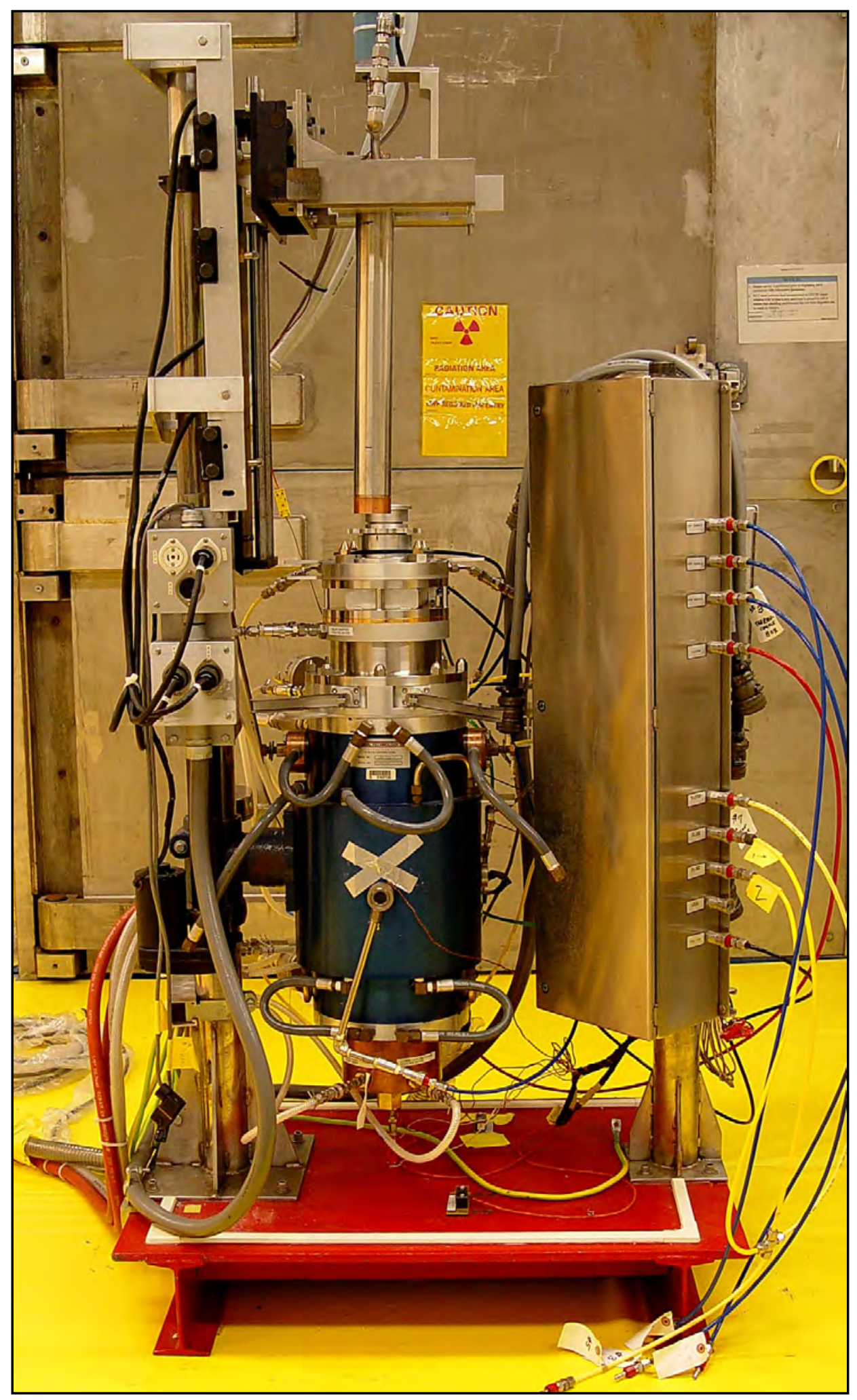

Appendix Figure A-2. CCCTF furnace in front of walk-in hood. 


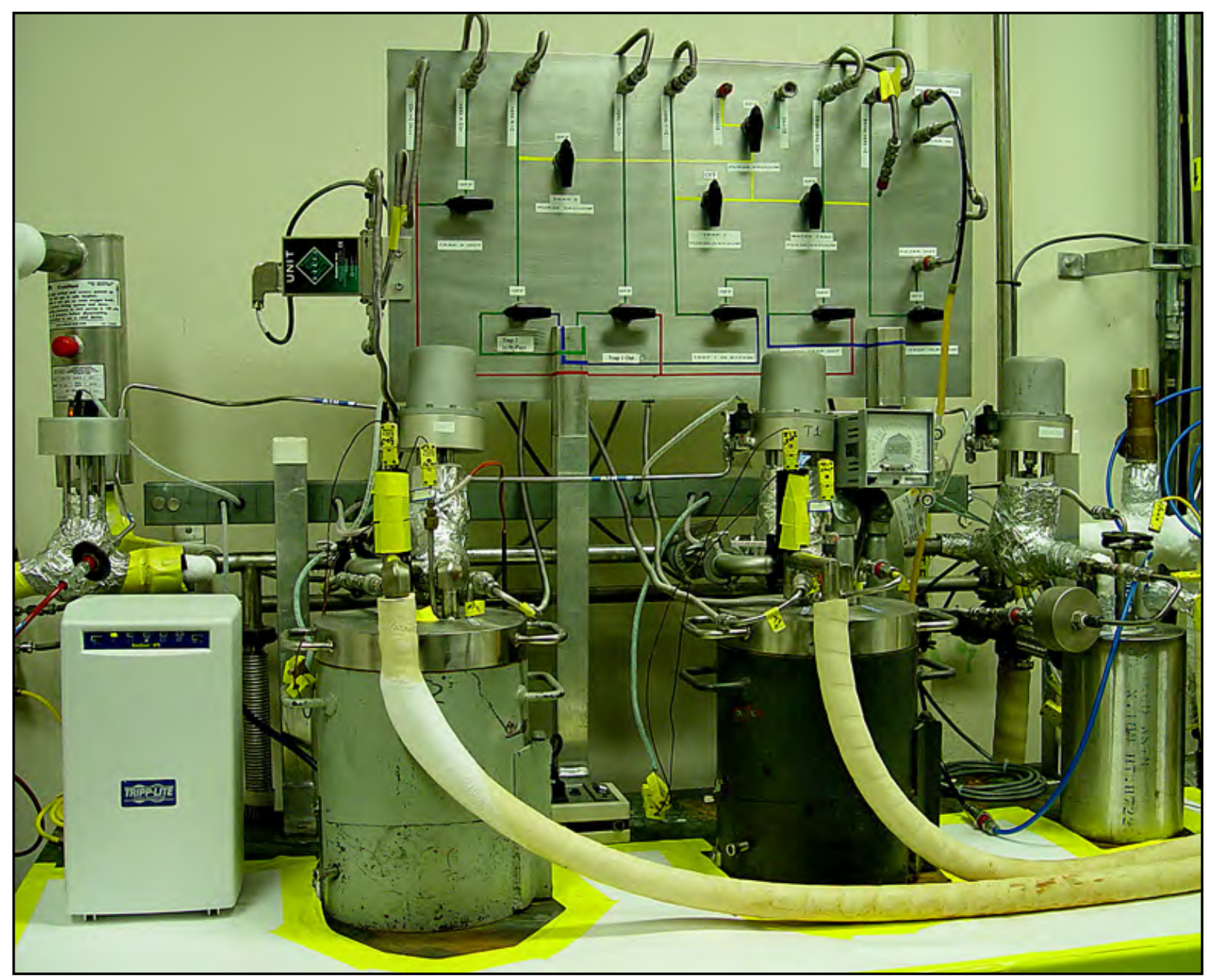

Appendix Figure A-3. CCCTF fission gas trap assembly. 


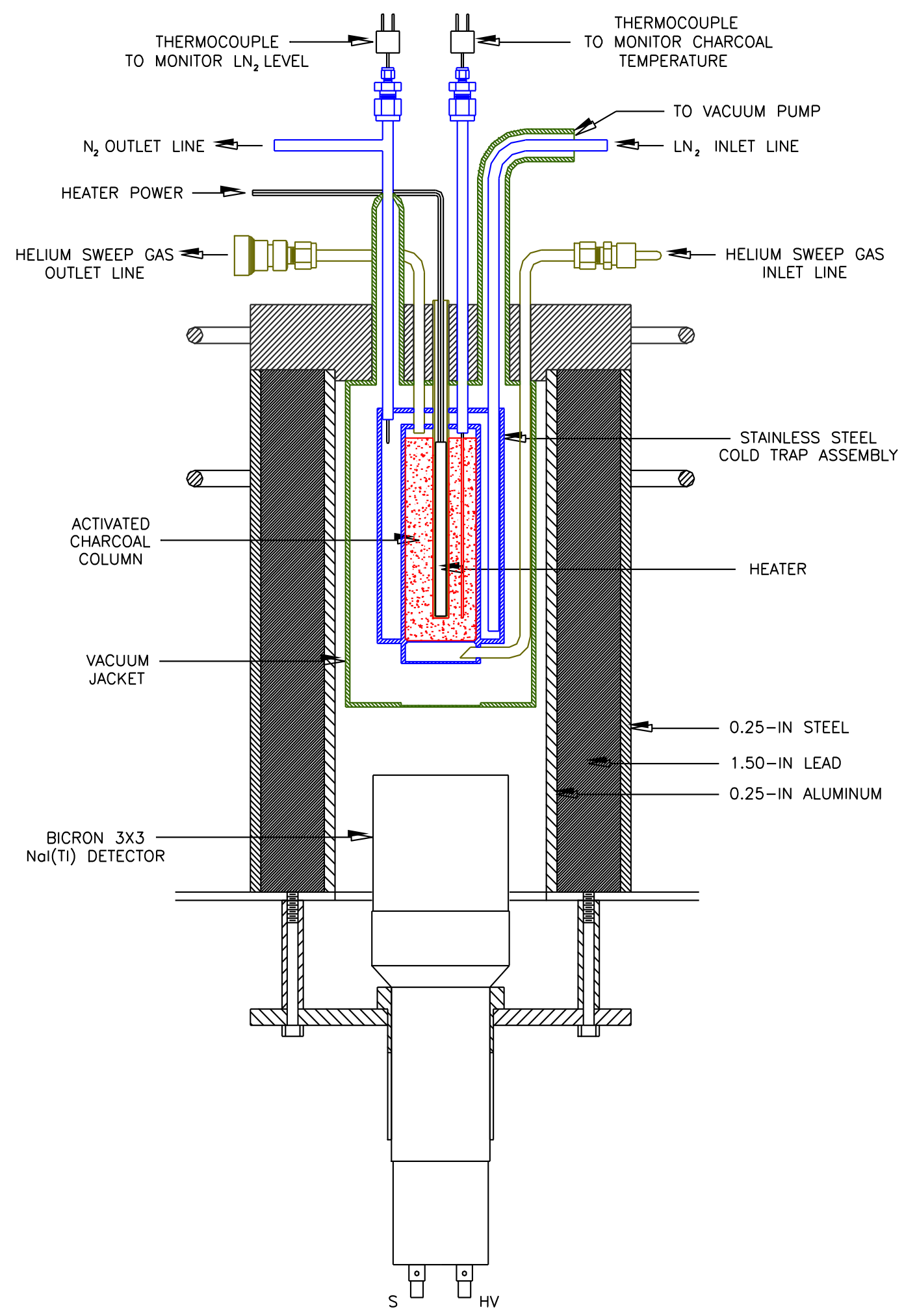

Appendix Figure A-4. Schematic of a liquid-nitrogen-cooled charcoal trap before 2017 redesign. 


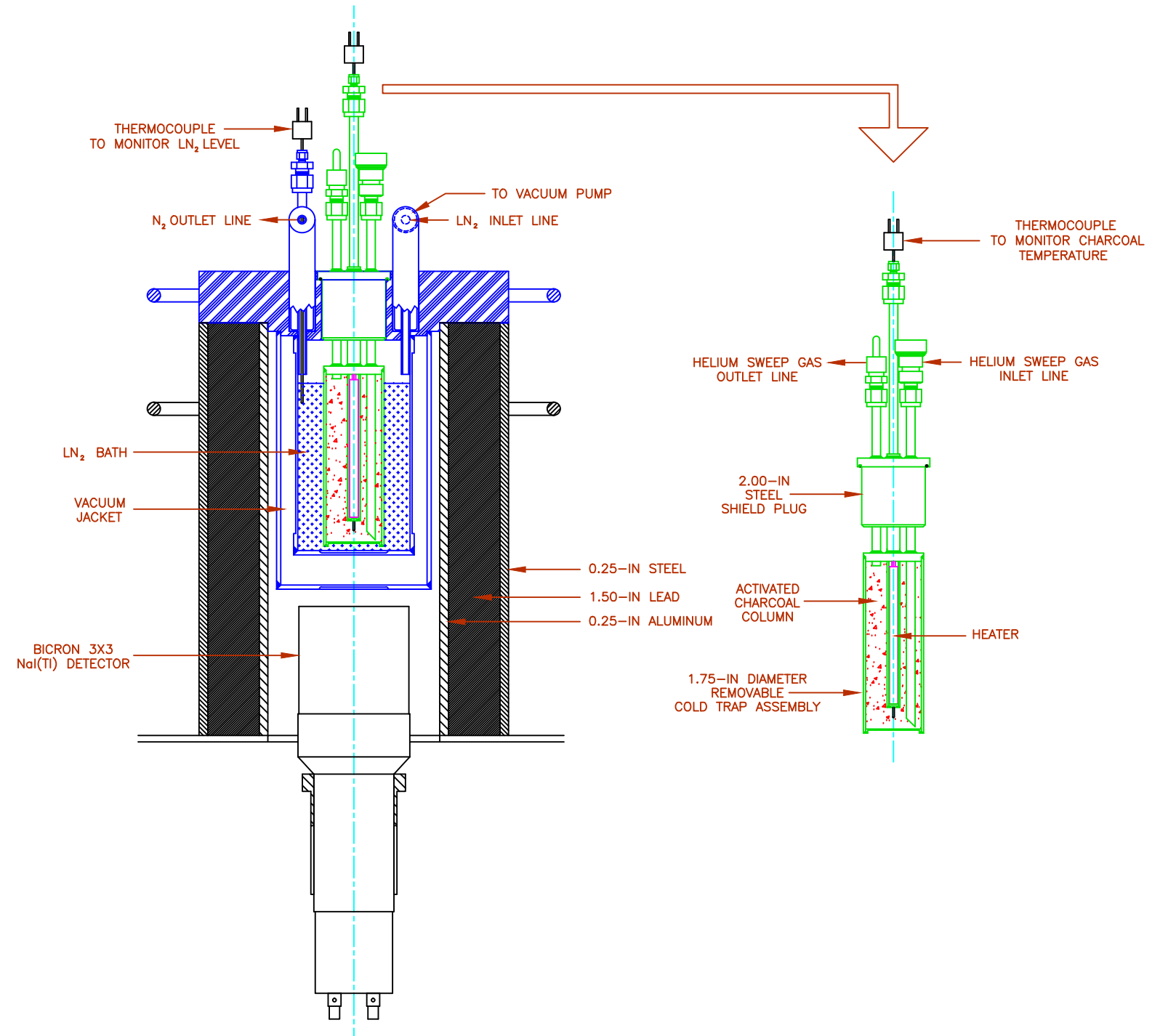

Appendix Figure A-5. Schematic of a liquid-nitrogen-cooled charcoal trap after 2017 redesign. 


\section{APPENDIX B. IMGA SYSTEM ${ }^{\dagger}$}

The current generation of the ORNL Irradiated Microsphere Gamma Analyzer was developed at ORNL in the early 1990s to replace the original IMGA system with one that utilized modern computer-automated motion control (Morris and Baldwin 2010b). The IMGA is designed to evaluate large numbers of individual High-Temperature Gas-Cooled Reactor (HTGR) coated fuel particles (microspheres). The evaluation involves determining the integrity or permeability of the particle coating based on the coating's ability to retain volatile fission products. Particles for examination are usually obtained by electrolytic deconsolidation of irradiated compacts composed of coated fuel particles and a graphite matrix binder. Once a compact has been deconsolidated, simple sieving and tabling techniques are used to separate the debonded particles from the matrix debris. The particles are then individually examined using a gamma spectrometer to measure the absolute inventory of key fission products. The ratio of a volatile to a nonvolatile fission product (e.g. ${ }^{137} \mathrm{Cs}$ to ${ }^{144} \mathrm{Ce}$ ) is used to determine the retention characteristics of the coating. Low-retention or damaged coatings will show a drop in the relative concentration of the more volatile species.

The IMGA system is composed of two highly integrated subsystems. The first subsystem is the MCA and its software, which are used to acquire and analyze the gamma-ray spectrum produced from the decay of fission products in the coated fuel particle under observation. The second subsystem is an in-cell particle handling device designed to transport individual particles from the storage carousel on one side of a lead shield to the counting position on the other side of the shield. The IMGA particle handling device is a combination of off-the-shelf and custom designed components. The off-the-shelf parts consist of a Parker Daedal three-axis motion control system (vertical, horizontal, and rotary) and an SMC Corporation of America vacuum ejector system, which are coupled together and controlled by a Parker Automation $6 \mathrm{~K}$ Series four-axis controller. The major subsystems of the IMGA are controlled by a desktop computer running an ORNL-developed program using the VB.NET programming module in Microsoft Visual Studio. This interface allows the user to input all the information necessary to perform an examination, including the mode of operation and any parameters required for real time analysis.

Two modes of operation for the IMGA system are supported. In the standard mode of operation, a single coated fuel particle is selected from a batch of particles located in taper-bottomed "v-vials" stored in the sample carousel (see Appendix Figure B-1). The particle is picked up by a vacuum transport system that sends a voltage signal to the control program allowing the program to "know" that a particle has been successfully acquired. The transport system then lifts the particle up and over the internal shielding and positions it in front of the counting port where the gamma-ray spectrum is acquired. A real time analysis is then performed to evaluate the retention characteristics of the particle coating. Based on the analysis a new location in the storage carousel is selected. Typically, a group of vials will be allocated for non-failed particles and another vial or group of vials will be allocated for failed particles. There is considerable flexibility in the way the particles can be sorted and stored. Ultimately the particle is placed into to the appropriate vial and the process is repeated until the batch of input particles is depleted. Data from the entire batch of particles is used to analyze particle frequency distributions and establish a statistical basis for performance of the fuel. This mode also has the advantage of separating particles of special interest (lower fission product inventory) from a larger batch of particles.

\footnotetext{
$\dagger$ Text and figures in this appendix were extracted, condensed, and edited from a previous milestone letter report [Morris and Baldwin 2010b].
} 


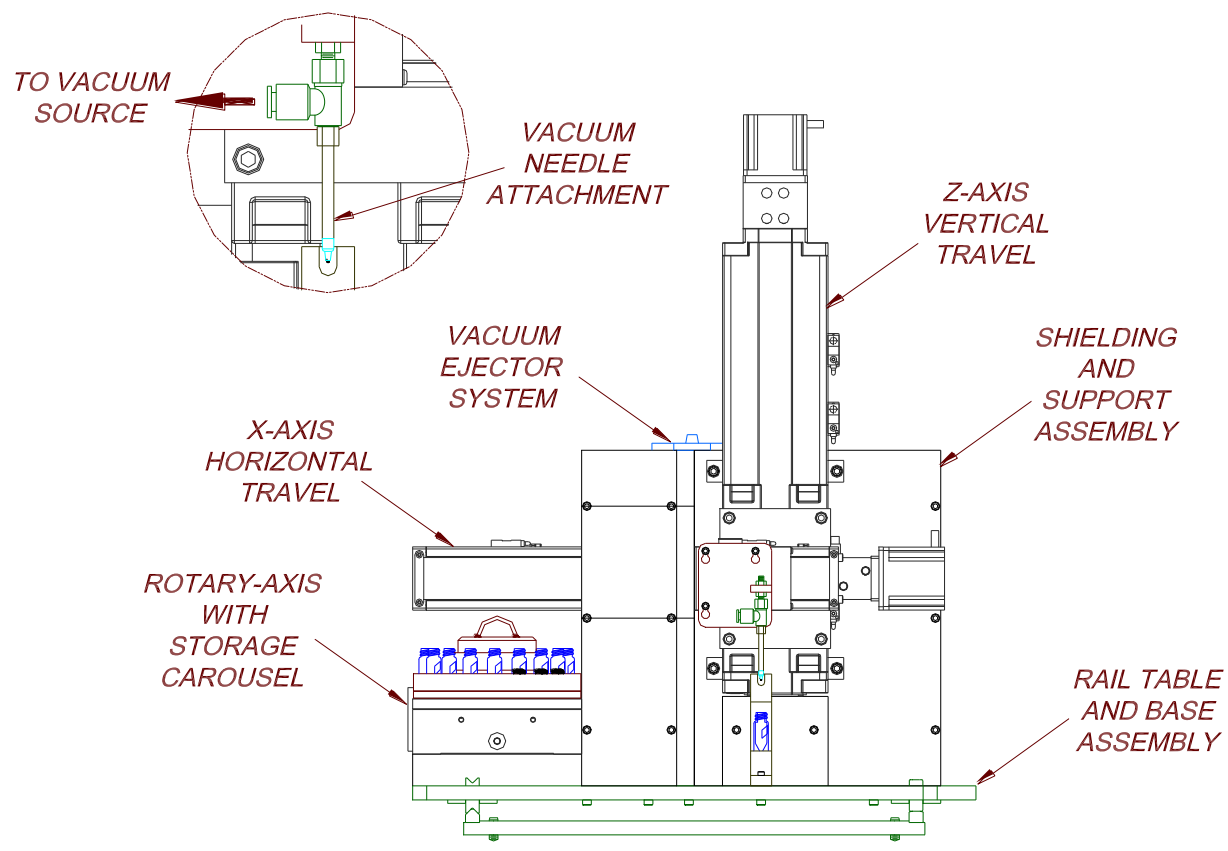

Appendix Figure B-1. Schematic of IMGA particle handling device configured in particle mode.

A secondary mode of operation is also supported where individual fuel particles are preloaded into v-vials (see Appendix Figure B-2). In this mode of operation, the loaded vial is picked up from the storage carousel using a small vacuum pad and positioned in front of the counting port. A gamma-ray spectrum is then acquired and saved for later offline analysis. The vial is then returned to its original location in the storage carousel. This process continues until all the vials in the carousel have been examined. This mode of operation has the advantage of maintaining the unique identity of each individual fuel particle and is commonly used when particles are to be used in a test where pre- and post-test measurements are desired.

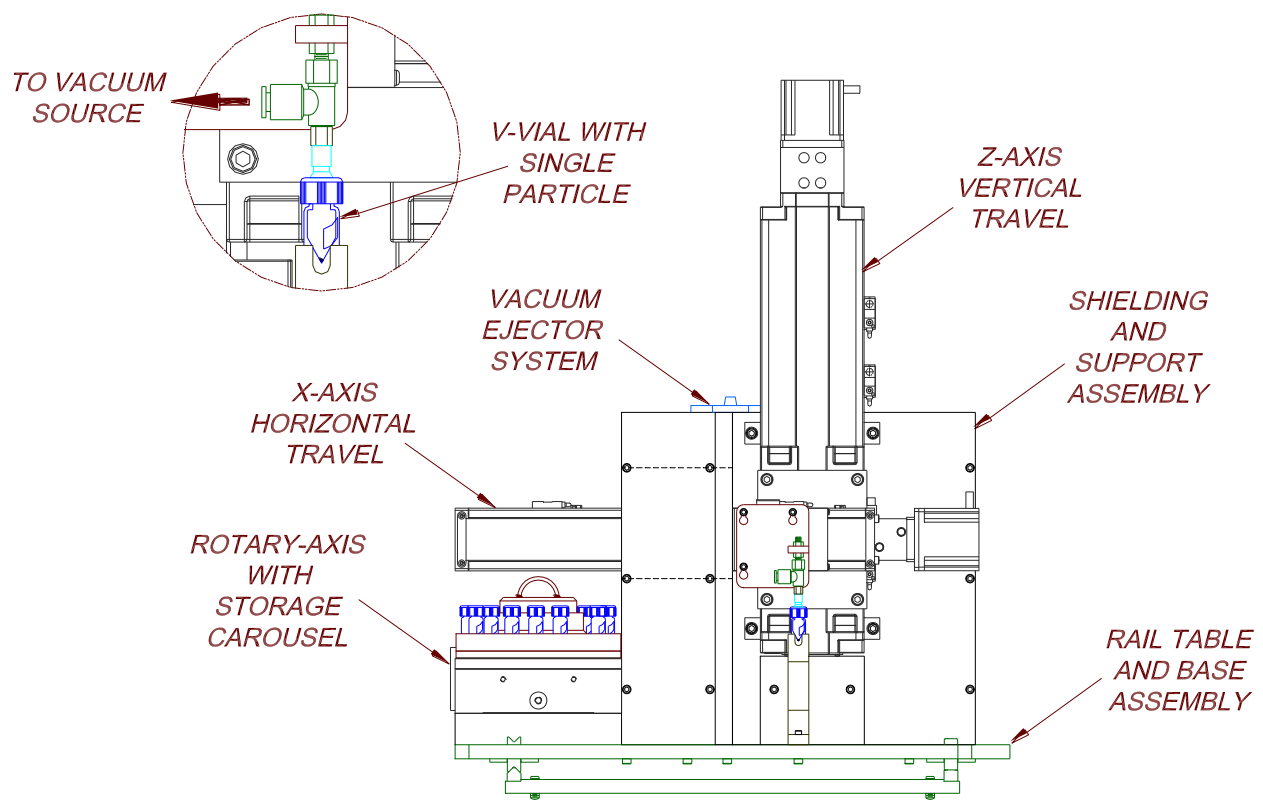

Appendix Figure B-2. Schematic of IMGA particle handling device configured in vial mode. 
When converting the particle handler from one mode of operation to the other, the only major hardware difference is the vacuum pad attachment. In the batch mode of operation, the vials in the storage carousel are of a special design to accommodate the vacuum needle used to pick them up and are not capped. In the individual more of operation, the vials are off the shelf specimen glass vials with caps on to retain the particles. A carousel tray cover (not shown) is provided for handling the storage tray when open vials are used so they are not spilled.

Photographs of the IMGA particle handling device constructed in 2010 are shown in Appendix Figure B-3 and Appendix Figure B-4. These images were taken after completion of the bench testing and before the equipment was transferred into the hot cell cubicle that was previously installed at ORNL to house the first generation IMGA device.

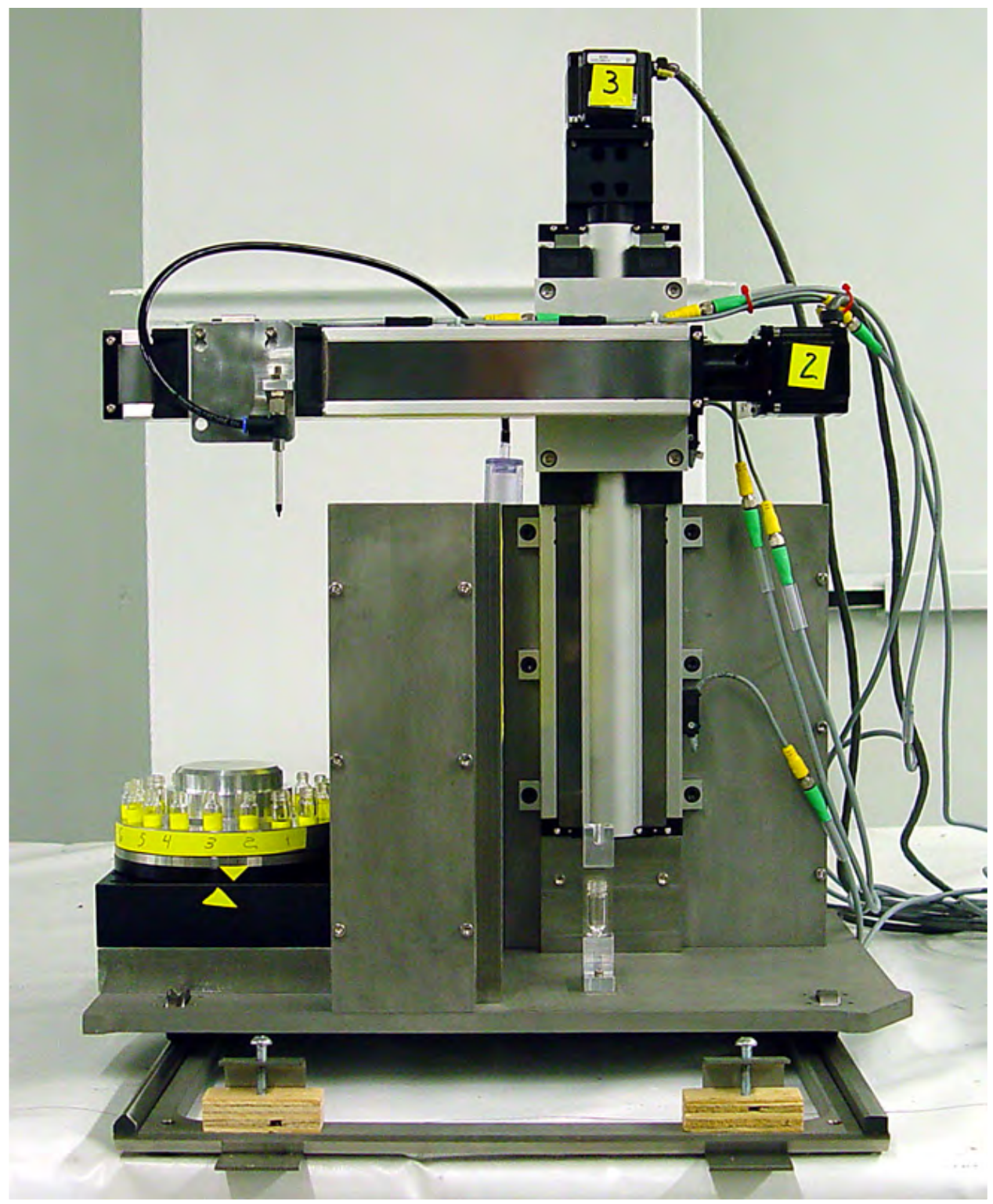

Appendix Figure B-3. Front side of IMGA particle handling device before installation in cell. 


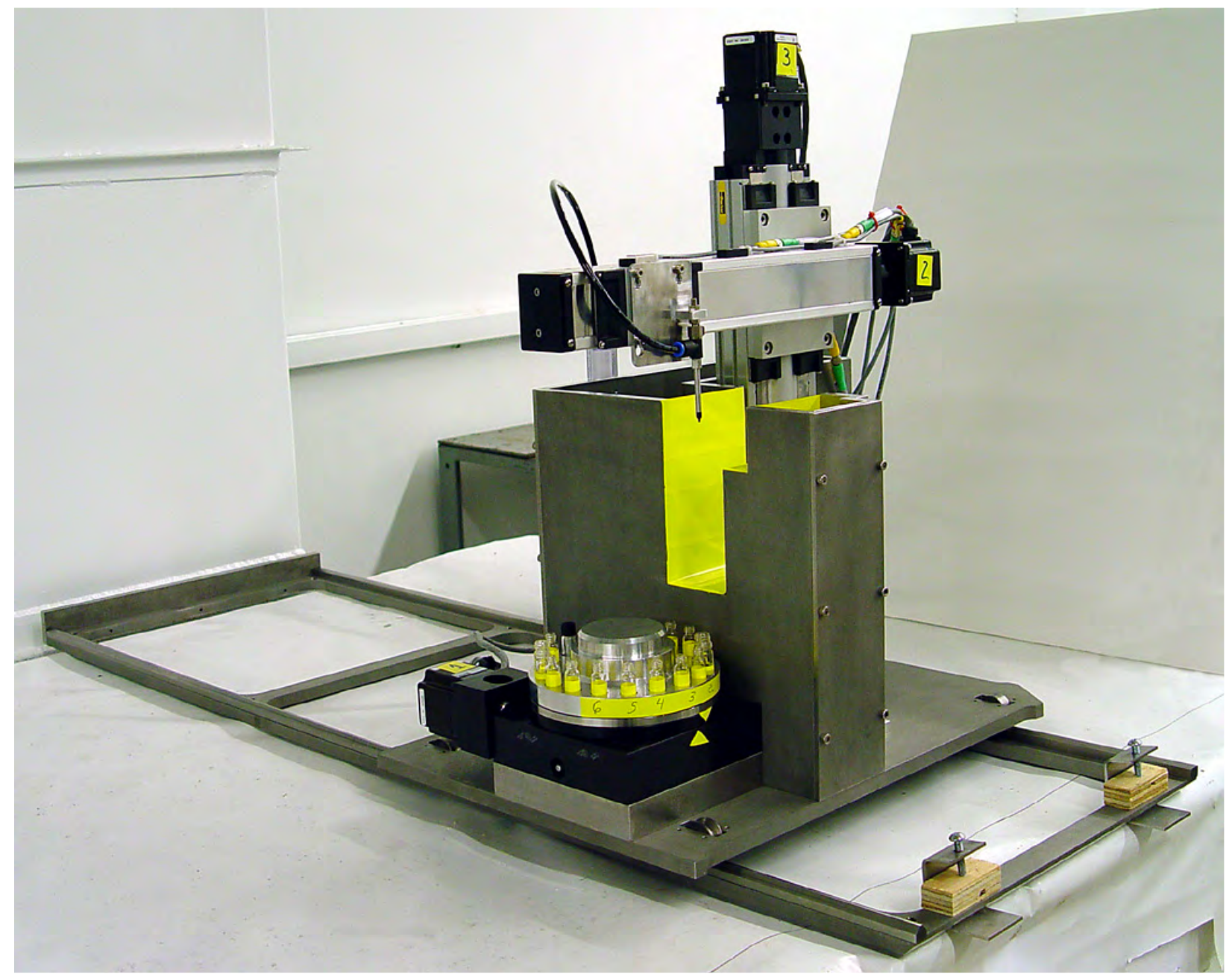

Appendix Figure B-4. Angle view of IMGA particle handling device before installation in cell showing the particle passing through the opening in the sample carousel shield block. 



(n)

